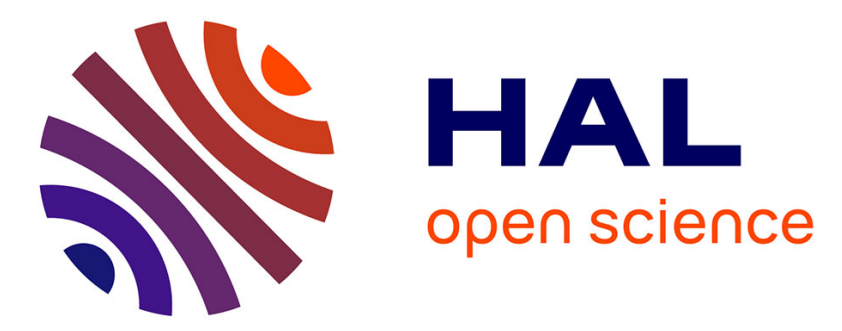

\title{
Uncertainties in probability of occurrence of strong earthquakes for fault sources in the Central Apennines, Italy
}

Aybige Akinci, David Perkins, Anna Maria Lombardi, Roberto Basili

\section{- To cite this version:}

Aybige Akinci, David Perkins, Anna Maria Lombardi, Roberto Basili. Uncertainties in probability of occurrence of strong earthquakes for fault sources in the Central Apennines, Italy. Journal of Seismology, 2008, 14 (1), pp.95-117. 10.1007/s10950-008-9142-y · hal-00478442

\section{HAL Id: hal-00478442 \\ https://hal.science/hal-00478442}

Submitted on 30 Apr 2010

HAL is a multi-disciplinary open access archive for the deposit and dissemination of scientific research documents, whether they are published or not. The documents may come from teaching and research institutions in France or abroad, or from public or private research centers.
L'archive ouverte pluridisciplinaire HAL, est destinée au dépôt et à la diffusion de documents scientifiques de niveau recherche, publiés ou non, émanant des établissements d'enseignement et de recherche français ou étrangers, des laboratoires publics ou privés. 


\title{
Uncertainties in probability of occurrence of strong earthquakes for fault sources in the Central Apennines, Italy
}

\author{
Aybige Akinci • David Perkins • \\ Anna Maria Lombardi • Roberto Basili
}

Received: 14 December 2007 / Accepted: 25 September 2008 / Published online: 12 November 2008

(C) Springer Science + Business Media B.V. 2008

\begin{abstract}
Using the characteristic earthquake model, we calculate the probability of occurrence of earthquakes $M_{\mathrm{w}}>5.5$ for individual fault sources in the Central Apennines for the 30-year period (2007-2037). We show the effect of timedependent and time-independent occurrence (Brownian passage time (BPT) and Poisson) models together with uncertain slip rates and uncertain maximum magnitudes and, hence, uncertain recurrence times. In order to reduce the large prior geological slip rate uncertainty distribution for most faults, we obtain a posterior slip rate uncertainty distribution using a likelihood function obtained from regional historical seismicity. We assess the uncertainty of maximum magnitude by assuming that the uncertainty in fault width and length are described by a normal distribution with standard deviation equal to $\pm 20 \%$ of the mean values. We then estimate the uncertainties of the 30-year probability of occurrence of a
\end{abstract}

\footnotetext{
A. Akinci ( $\square)$ · A. M. Lombardi · R. Basili Istituto Nazionale di Geofisica e Vulcanologia, Via di Vigna Murata 605, 00143 Rome, Italy e-mail: akinci@ingv.it

D. Perkins

US Geological Survey, MS 966, Box 25046,

Denver, CO 80225, USA

e-mail: perkins@usgs.gov
}

characteristic event using a Monte Carlo procedure. Uncertainty on each parameter is represented by the 16th and the 84th percentiles of simulated values. These percentiles bound the range that has a $68 \%$ probability of including the real value of the parameter. We do these both for the Poisson case and for the BPT case by varying the aperiodicity parameter ( $\alpha$ value) using the values $0.3,0.5$, and 0.7. The Bayesian posterior slip rate uncertainties typically differ by a factor of about 2 from the 16th to the 84th percentile. Occurrence probabilities for the next 30 years at the 84 th percentile typically range from $1 \%$ to $2 \%$ for faults where the Poisson model dominates and from $2 \%$ to $21 \%$ where one of the BPT models dominates. The uncertainty in occurrence probability under the time-dependent hypothesis is very large, when measured by the ratio of the 84 th to the 16 th percentile, frequently being as much as two orders of magnitude. On the other hand, when measured by standard deviation, these standard deviations range from $2 \%$ to $6 \%$ for those faults whose elapsed time since previous event is large, but always $2 \%$ or less for faults with relatively recent previous occurrence, because the probability of occurrence is always small.

Keywords Probability of occurrence •

Time dependent • Uncertainties • Aperiodicity • BPT $\cdot$ Monte Carlo simulations • Central Apennines, Italy 


\section{Introduction}

Probabilistic seismic hazard analysis (PSHA) provides the conceptual framework for estimating the likelihood of earthquake shaking that may occur over a specified time period. It has become common practice to apply (PSHA) to develop seismic hazard maps for input to various projects related to public and financial policies and for mitigating damage in future earthquakes. PSHA has two main components: (1) the earthquake occurrence model, that is, the specification of where and how frequently earthquakes are likely to occur, and (2) a ground motion model that provides an estimate of shaking at a site for each earthquake magnitude. By now, it is a common understanding among hazard practitioners that probabilistic seismic hazard is affected by large uncertainties that are inherent in the estimation of these components (Cramer et al. 1996; Cramer 2001; Beauval and Scotti 2004; Bommer et al. 2005; Cao et al. 2005; Lombardi et al. 2005; Morgan and Carlson 2006; Akinci et al. 2007). The present study focuses only on the first component of PSHA, the uncertainties in probability of occurrences of strong earthquakes for specified faults, and does not deal with the relative ground motion produced by the earthquake rupture.

One of the most commonly used earthquake occurrence models is the Poissonian, where the earthquake process is assumed to have no memory, i.e., the occurrence of a future earthquake is independent of the occurrence of previous earthquakes from the same source. Although possibly valid for areal sources, this assumption is physically not valid for individual fault source, given that the process of stress buildup and its release is inherently time dependent. In fact, in recent years, time dependence has become increasingly a part of probabilistic seismic hazard analysis (e.g., Cramer et al. 2000; Akinci et al. 2004a, b; Erdik et al. 2004; Pace et al. 2006; Peruzza 2006; Petersen et al. 2007). Accordingly, in the case of fault sources, the time variation of earthquake occurrence rate in seismic hazard assessment is mainly represented by applying non-Poissonian renewal models on individual sources. These are generally in agreement with Reid's (1910) theory of the periodicity of fault slips (Nishenko and
Buland 1987; Ellsworth et al. 1999) and of seismic gap theories (McCann et al. 1979).

Even though periodicity is commonly assumed by experts in hazard assessment, the debate on basic intermediate-long-term features of seismogenetic process is still open. Despite some decades of effort, there is no conclusive assertion about long-term dynamics of seismic activity. The most resolute criticism of hazard calculations based on periodicity of fault recurrence was raised by Kagan and Jackson (1991). By analyzing occurrence of strong events in recent decades, they concluded that performance of the seismic gap model is not better than a Poisson process because a clustering behavior, not quasiperiodicity, characterizes the occurrence of large-magnitude earthquakes. More recently, other studies (Rhoades and Evison 2004; Lombardi and Marzocchi 2007) have corroborated the hypothesis of long-term clustering of large-magnitude events at regional and global scales, highlighting the superior performance of clustering and Poisson models with respect to the quasiperiodic model.

Despite the criticism of the seismic gapcharacteristic occurrence hypothesis, no study has irrefutably proved the failure of the "quasiperiodicity" of sources, so that it remains the preferred model for a hazard-oriented earthquake potential evaluation. Accordingly, in this paper, we assume a periodic earthquake recurrence on individual fault as our working hypothesis.

Although time-independent characterization of earthquake source behavior requires only an assessment of the average time of recurrence for a given magnitude, time-dependent hazard assessment additionally requires knowledge of both the time elapsed since the last earthquake and also the characterization of the degree of periodicity. Time dependence is typically applied to larger-magnitude earthquakes modeled as characteristic events on a single fault, with magnitudes close to a central value $M_{\mathrm{ch}}$ (characteristic earthquake model; Schwartz and Coppersmith 1984), leaving smaller earthquakes to be modeled with a Gutenberg-Richter (GR) distribution and time-independent occurrence. However, the determination of $M_{\mathrm{ch}}$ values and recurrence times conceals many difficulties. The length of instrumental and historical seismic catalogs is generally 
inadequate to comprehend the entire temporal cycle of individual sources, which typically have a characteristic recurrence time on the order of a few centuries or more, even up to a few millennia. In addition, requirements for collecting and interpreting paleoseismological data are not always satisfied in all seismogenic zones, especially where surface-breaking faults are uncommon. Therefore, the characterization of individual sources (slip rate, magnitude, and recurrence time) needs to be based on longer-term, more uncertain, geologic features.

In the last decade, there has been an increasing interest in assessing earthquake probabilities and seismic hazard incorporating detailed knowledge of active faulting and tectonic rates in earthquake recurrence models in Italy (GNDT2004, Gruppo Nazionale di Difese dei Terremoti; MISHA-1999, Methodi Innovativi per la Stima dell'Hazard; DPC-S2-2007, Dipartmento della Protezione Civile, Valutazione del potenziale sismogenetico e probabilità dei forti terremoti in Italia; Peruzza et al. 1997; Faenza et al. 2003; Marzocchi et al. 2003; Akinci et al. 2004b; Romeo 2005; Pace et al. 2006). In this context, the modeling of time-dependent characteristic sources has also become important.

Because hazard studies are important for their practical implications for society and public policy decision-making processes, an appreciation for the uncertainties and limiting assumptions underlying such studies should be more broadly understood and communicated to the user and decision-making communities. To this end, in this study, we concentrate on calculating uncertainties both in the source parameters and in the earthquake recurrence model and then on assessing the resultant uncertainties in probability of occurrence of strong earthquakes, $M_{\mathrm{w}}>5.5$, in the next 30 years. As a target area, we have chosen the Central Apennines region where the activefault catalog is more complete and where most of the past $M_{\mathrm{w}}>5.5$ earthquakes have been associated with seismogenic structure. We used the individual sources included in the Database of Individual Seismogenic Sources (DISS), version 3.0.4 (DISS Working Group 2007), which are determined on the basis of a multitude of geological and geophysical data and characterized by a full set of geometric, kinematic, and behavioral parameters. These seismogenic sources (faults) are defined as those having both geologic evidence for long-term rupture histories and also an estimate of the elapsed time since the last earthquake. A simple elastic dislocation model predicts that the probability of an earthquake rupture increases with time as the tectonic loading builds stress on a fault. Thus, the elapsed time is the first-order parameter in calculating time-dependent earthquake probabilities. Although other parameters such as static elastic fault interactions, viscoelastic stress transfer, and dynamic stress changes from earthquakes on nearby faults will also influence the probabilities for earthquake occurrence, we consider only the influence of the elapsed time since the last earthquake.

We incorporate uncertainties for fault source parameters (fault length, fault width, and slip rates) and their resulting recurrence rates in the calculation of probability of occurrence without going further to assess the relative contribution of each fault to the seismic hazard, as would be done in PSHA. To quantify the uncertainties for $M_{\max }$ and recurrence rates of each fault segment, we used a Monte Carlo approach (e.g., Cramer et al. 1996) to calculate the distributions. The probability of occurrence for each fault was calculated using both Poisson and Brownian passage time (BPT) earthquake recurrence models for three different $\alpha$ values by varying the magnitude and recurrence times also in a series of Monte Carlo runs. Then, for each fault segment, the probability of occurrence was sorted into ascending order, and the 16th and 84th percentiles were identified.

\section{Database of individual seismogenic sources (DISS3.0.4) in the Central Apennines}

The DISS is a repository of geologic, tectonic, and active-fault data for the Italian territory and some surrounding regions (Basili et al. 2008). DISS includes three main categories of seismogenic sources based on their attributes, their expected use, and the nature and reliability of data used to define them.

"Individual Seismogenic Sources" (ISS) are defined by geological and geophysical data and are 
characterized by a full set of geometric (strike, dip, length, width, and depth), kinematic (rake), and seismological parameters (single event displacement, magnitude, slip rate, recurrence time). ISS are assumed to exhibit strictly periodic recurrence (sensu Shimazaki and Nakata 1980) determined only by rupture length-width, slip per event, and expected magnitude. "Seismogenic areas" also are based on geological and geophysical data but represent composite sources that may include a variable number of individual fault segments; as such, they are not suitable for this study and will not be modeled. "Macroseismic sources" are based on automatic processing of macroseismic data using the algorithm developed by Gasperini et al. (1999). All categories of seismogenic sources illustrated above have a minimum moment magnitude of 5.5. This threshold was adopted in the development of the DISS because the expected size of a fault generating an $M_{\mathrm{w}} 5.5$ earthquake (approximately $5 \mathrm{~km}$ ) is close to the limit of the resolving power for both geological-geophysical and macroseismic methods and can be considered a minimum to produce significant structural damage (Valensise and Pantosti 2001). In this study, we will only use the ISS and the macroseismic well-constrained sources (MWS). Figure 1 shows a map of the seismogenic sources included in our study area taken from DISS version 3.0.4 (DISS Working Group 2007).

Reducing geological-geophysical data into ISS parameters implies considering that length (L), width (W), single event displacement (D), and magnitude (M) are interconnected by seismological scaling relationships, such as those by Kanamori and Anderson (1975), Hanks and
Fig. 1 Earthquake sources used in this study, selected from the Database of Italy's Seismogenic Sources, latest version (3.0.4) released after the end of the DPC-2006 Project. We use two of the three kinds of sources: the geological sources (black rectangles) and the historical wellconstrained sources (white rectangles). Numbers refer to data rows given in Table 1. The third kind of sources was not used

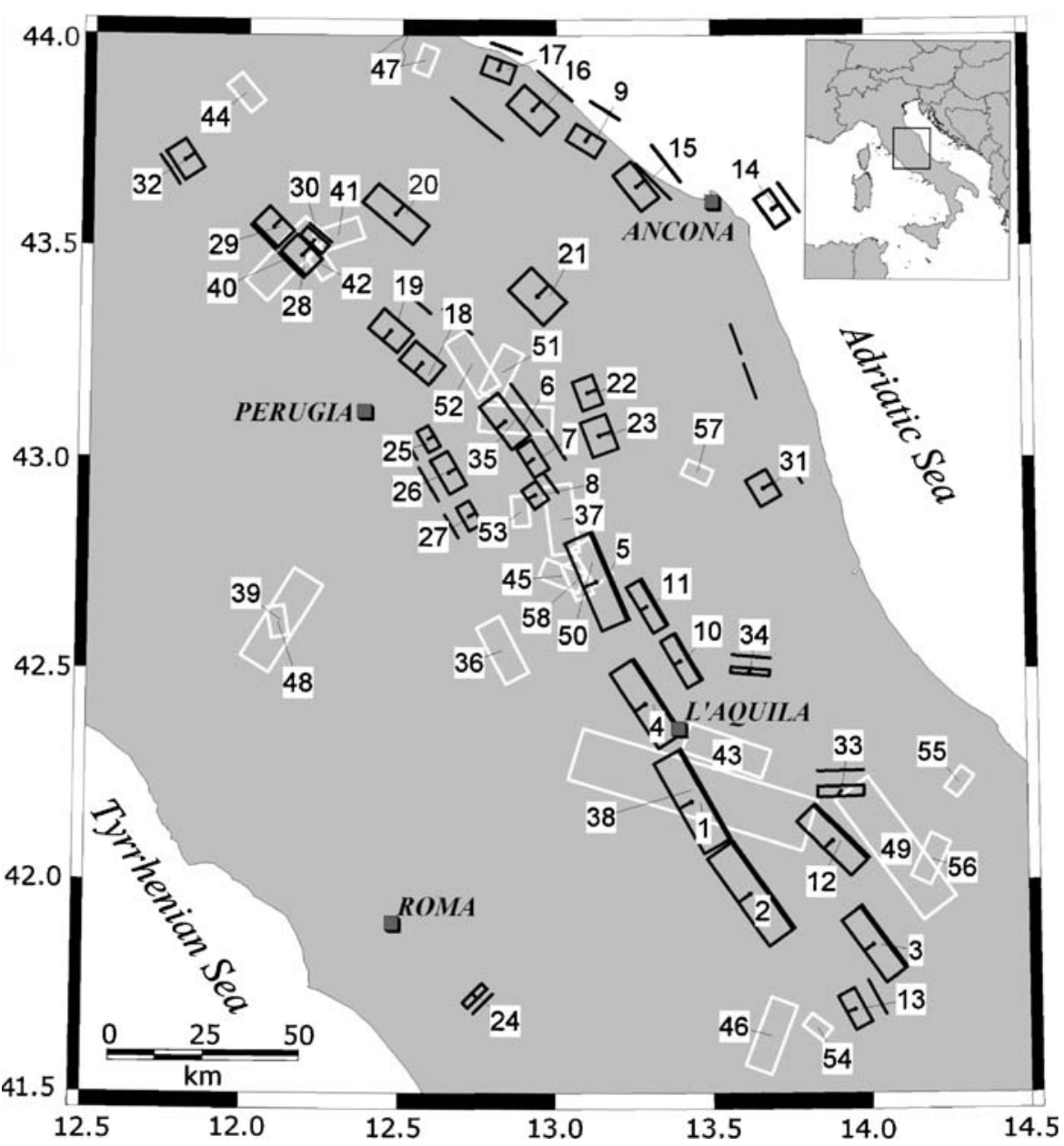


Kanamori (1979), and Wells and Coppersmith (1994). Therefore, DISS compilers verify the internal consistency of these parameters. The ideal case is when $L, W, D$, and $M$ are all known from independent observations. In this case, the different estimations can be used alternately with the scaling relationships, and the consistency of a seismogenic source with some generalized model can be analyzed. For what concerns the parameters of the ISS selected for this study, apart from the four sources, in all other cases, at least one among $\mathrm{L}, \mathrm{W}$, or $\mathrm{M}$ was determined through empirical relationships. Taking into account the accuracy of investigation methods and techniques, errors on $\mathrm{L}$ and $\mathrm{W}$ are usually within $\pm 2 \mathrm{~km}$ which implies, in most cases, an uncertainty of \pm 0.2 units in moment magnitude. Quaternary slip rate was estimated from local geological data for one third of the sources. For the remaining sources, the slip rate was estimated on the basis of geological reasoning at a much broader scale, the slip rate being set to a conventional range of $0.1-1 \mathrm{~mm} /$ year. The lower value is considered as the minimum amount for a fault to produce detectable geological offset; the upper value is set at the maximum rate; the hanging wall of normal faults can be downthrown to obtain maximum values of regional uplift rates during the Quaternary (Vannoli et al. 2004; Mariani et al. 2007; Mancini et al. 2007). This reasoning was initially developed for the normal faults aligned along the crest of the Apennines, which have the faster deformation rates, and then extended to all other slower sources. Slip rate estimates obtained through paleoseismological investigations rarely exceed the $0.1-1-\mathrm{mm} /$ year range (e.g., Pantosti et al 1996; Galadini and Galli 1999; D'Addezio et al. 2001); thus, we use this range also for the MWS.

The integrated dataset includes 34 ISS and 24 MWS. Within the first category, 26 are associated with a historical earthquake; two are associated with prehistorical earthquakes identified from paleoseismological studies, and six are not associated with any earthquake (latest earthquake referred to as "unknown" in Table 1). In this study, the last earthquake on these six faults is assumed to have occurred in 1530 based on the completeness of the historical catalogs for magnitudes greater than 5.5, and 477 years of elapsed time are used for the calculation of probability of occurrence.

The second category includes only the sources of historical earthquakes for which there exist good macroseismic intensities. For 13 sources out of 24 , at least 20 intensity data were available in the DBMI04 macroseismic database (Stucchi et al. 2007). On the whole, the integrated dataset of the two data categories account for 50 historical earthquakes. There are 60 earthquakes having $M \geq 5.5$ contained in the investigated area, according to the CPTI04 catalog (CPTI Working Group 2004); hence, the integrated dataset accounts for about $83 \%$ of all the large historical earthquakes in the area.

\section{Earthquake recurrence models}

In hazard studies, the total seismic moment release for a fault source is sometimes partitioned between two different magnitude-frequency recurrence models, the Characteristic or maximum magnitude model ( $\mathrm{CH}$ hereafter) which considers all moment release is associated with a single maximum magnitude and GR that considers that moment release is associated with earthquakes having a range of magnitudes between the minimum and maximum magnitude. Used together, the characteristic and GR models are meant to incorporate our uncertainty about the magnitude-recurrence behavior for a particular fault. However, the geological and historical individual sources defined in DISS follow "the basic assumption that each seismogenic source tends to generate repeatedly and exclusively its largest allowed earthquake, that is the assumption of 'characteristic' behavior (in the sense of Schwartz and Coppersmith 1984) for what concerns fault location, geometry and size." (Valensise and Pantosti 2001, p. 802). Therefore, in this study, the longterm seismic potential of a fault segment has been modeled by the characteristic earthquake model.

The behavior of each source is assessed by the magnitude of the characteristic event $\left(M_{\max }\right)$ and its mean recurrence time $\left(T_{\text {bar }}\right)$. Given the recurrence model, we derive the earthquake recurrence rate of the individual sources in a straightforward manner from slip rate and magnitude, using the 


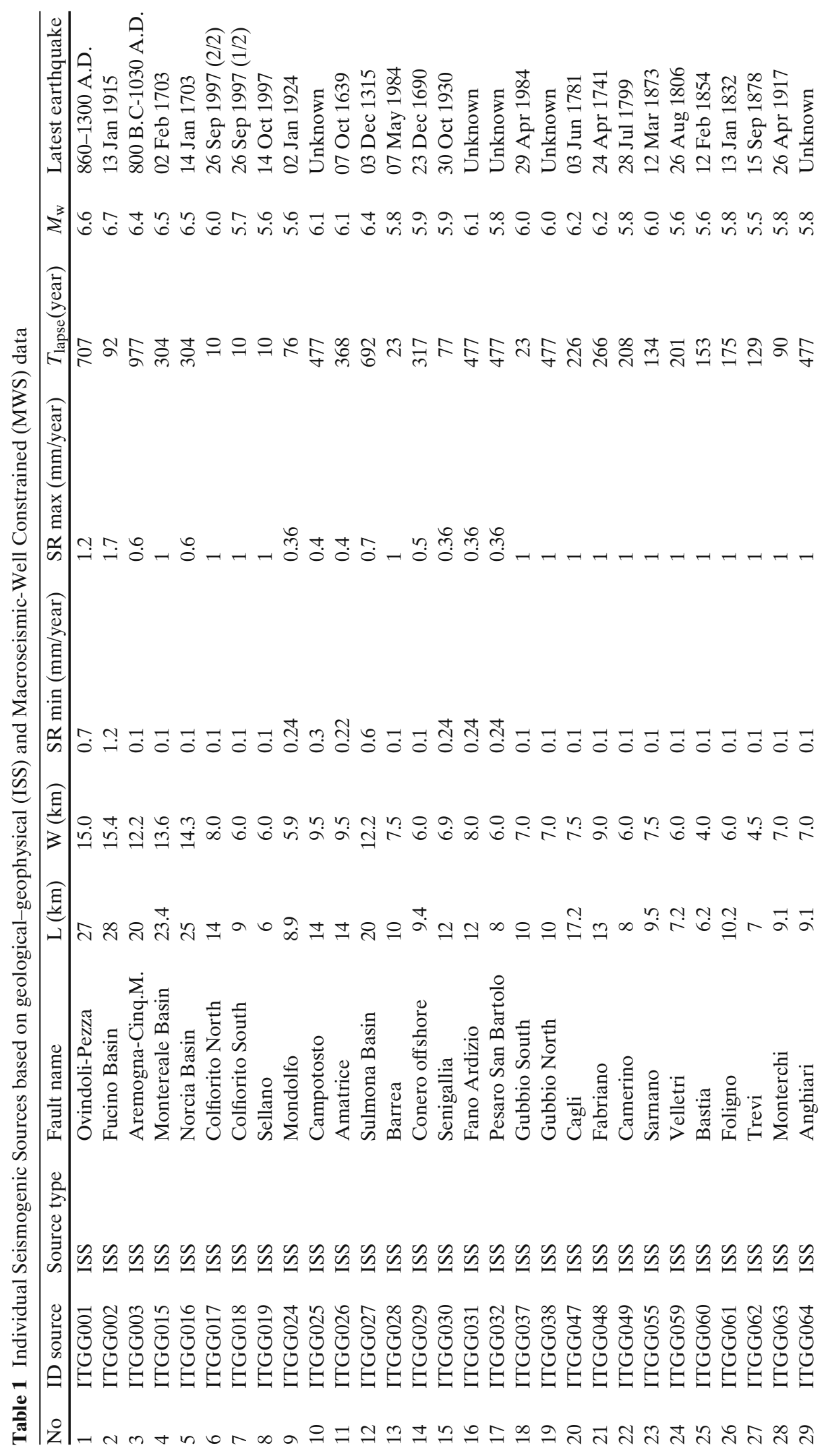




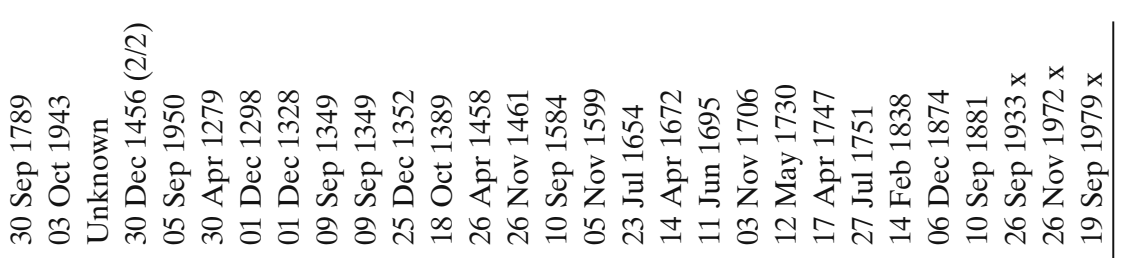

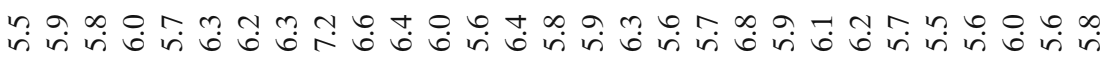

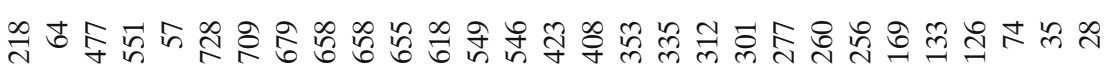

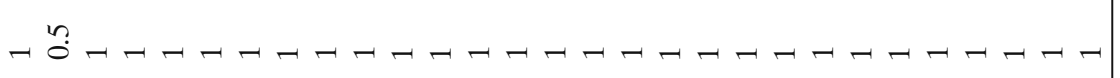

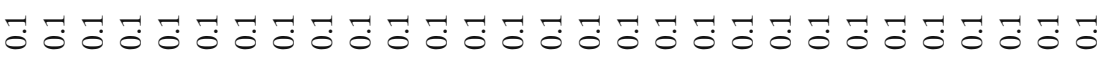

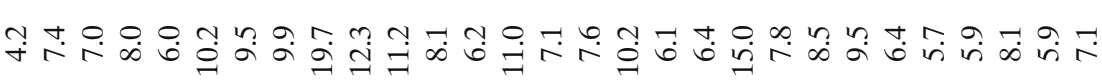

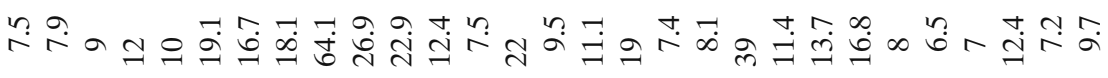

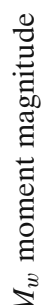

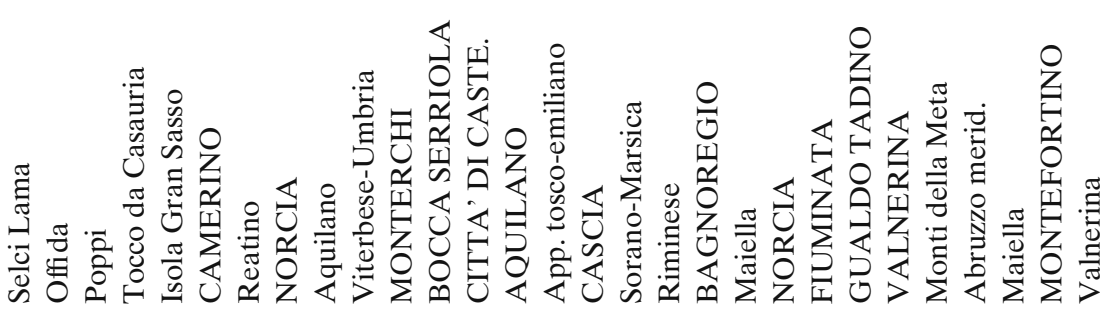

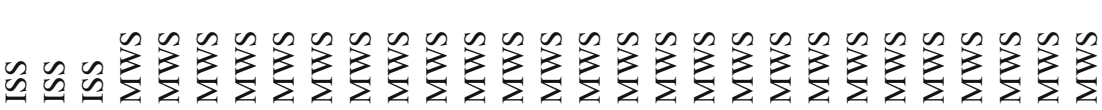

そ융유

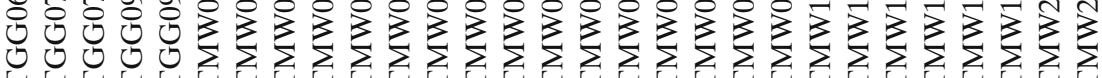

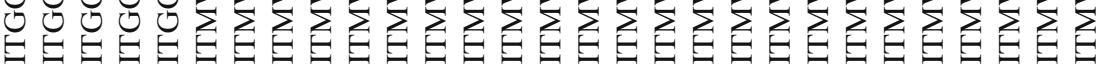

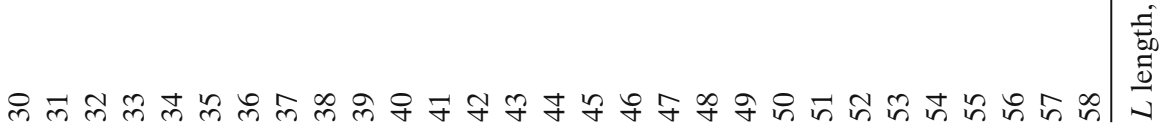


technique known as the conservation of the seismic moment rate on the fault segment given by Field et al. (1999):

RateCH $=\mu \times L \times W \times \mathrm{SR} / 10^{c \times M_{\mathrm{w}}+d}$

where, RateCH is the annual rate of the earthquakes on the source, $\mu=$ shear modulus, $L=$ fault length, $W=$ fault width, calculated using the fault depth and the dip, SR = slip rate; $c=$ 1.5 and $d=9.05$ are from the moment magnitude relation $\left(\log M_{\mathrm{o}}=c \times M_{\mathrm{w}}+d\right)$, and $M_{\mathrm{w}}=$ characteristic or maximum magnitude from DISS3.0.4.

Table 1 gives the necessary information related with the fault geometry (length, $L$, width, $W$ ) and its seismic behavior (slip rates, SR, maximumcharacteristic magnitude, $M_{\max }$ ) as defined in the DISS3.0.4 database together with the recurrence time calculated using minimum and maximum slip rates for each individual source. Since most of the sources are characterized by a regional "reasonable" slip rate varying from 0.1 to $1.0 \mathrm{~mm} / \mathrm{year}$, the variability of the return times is quite large and may vary from hundreds to thousands of years.

\section{Deriving a recurrence rate distribution}

In our study, we want to quantify the uncertainty in earthquake occurrence probability using some uncertain input parameters (e.g., slip rate, maximum magnitude, and recurrence rates). To do so, we have to quantify the uncertainty in the input parameters by obtaining probability distribution functions for each parameter. The first input parameter that we take into account is the slip rate.

\subsection{Definition of probability density functions for slip rate}

In DISS3.0.4, only 12 of the 58 faults have slip rates estimated from local geological data. For the remaining sources, the slip rate is estimated on the basis of geological reasoning at a much broader scale. In all these cases, slip rate is set to a conventional range of 0.1-1.0 mm/year. Significant differences exist among the recurrence rates calculated using the higher and lower values of this proposed range. We sought to devise narrower distribution functions for these slip rates, particularly for the
$0.1-1.0$ category. In consultation with geologists, we found that the lower limit represented a value below which tectonic expression might not be at all evident. The upper limit was not an actual limit but a conventional value; rates above $1.5 \mathrm{~mm} / \mathrm{year}$ would probably generate too much tectonic expression. Given the range of values, we believed that a long-tailed lognormal distribution would express the tectonic uncertainty better than a symmetric normal distribution. We set the parameter values so that 0.1 would be very clearly a lowprobability low slip rate value, but a slip rate of 1.0 could be significantly exceeded, and a value around 1.5 is the corresponding low-probability high slip rate value. The curve labeled "prior" in Fig. 2 is the resulting lognormal probability distribution which we chose to represent the slip rate distribution for the faults in the $0.1-1.5-\mathrm{mm} / \mathrm{year}$ category.

In order to reduce this large slip rate uncertainty for this category of faults, we decided to use an approach based on Bayes' law, in which the product of a prior distribution and a likelihood distribution produces a posterior distribution. In

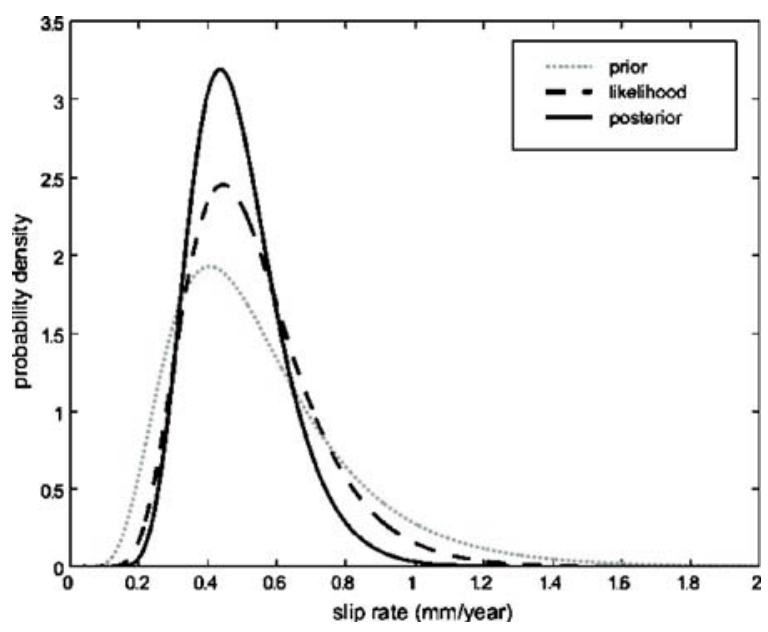

Fig. 2 Slip rate functions defined using Bayes' law. The prior function was assumed from interpretation of geologic constraints. The likelihood function was defined considering the misfit between the log of the cumulative number of events per year in the CPTI04 catalog and the log of the cumulative number of events per year predicted from the characteristic earthquake model for all 58 faults, with identical slip rates varying between 0.1 and $2.5 \mathrm{~mm} /$ year on each fault. The posterior function is given from the product of the prior and the likelihood and is given by Eq. 2 
our case, the prior geological slip rate distribution is modeled as a lognormal probability distribution. To obtain a likelihood, we sought to express the effect on predicted seismicity of assuming for all the faults in this category a single slip rate in the range of 0.1 to 2.5. Figure 3 shows the historical cumulative rate and three examples of predicted rates under slip rate assumptions of $0.1,0.5$, and $2.0 \mathrm{~mm} /$ year. The misfit between the $\log$ of the cumulative predicted rate at each magnitude and the $\log$ of the cumulative historically observed rate was used to generate a likelihood function. Specifically, for each assumed slip rate, we took the difference in the observed and assumed log rates at each magnitude, normalized it by an estimated standard deviation, squared the result, summed over all magnitudes, and placed the sum as the argument of a negative exponential. The resulting likelihood function is another long-tailed unsymmetrical distribution but narrower than the prior.

The normalizing standard deviation was estimated by the following process: A standard deviation for the observed number at each magnitude was taken to be the square root of the observed number, as would be so for Poisson numbers. This standard deviation was scaled for rate. The standard deviation for $\log$ rate was calculated using the formula: $\mathrm{SD}(\log x)=\log ((\operatorname{SD}(x))+$ mean $(x)) /$ mean $(x))$. Notice that the resulting standard

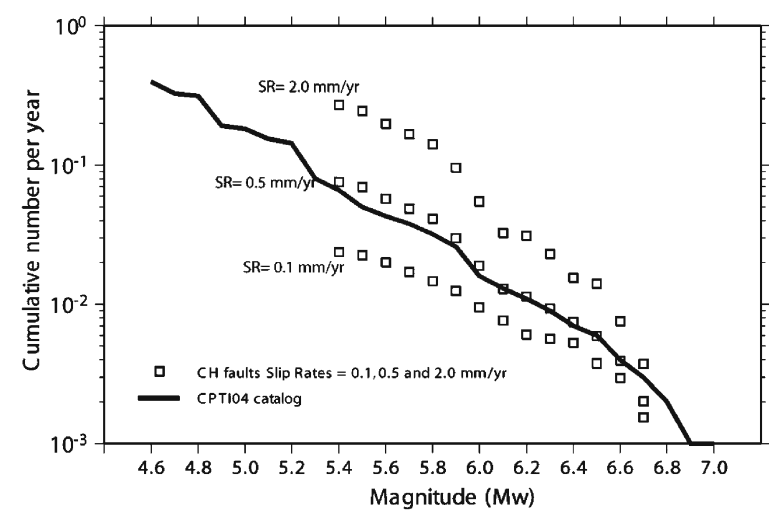

Fig. 3 Cumulative number of events per year versus magnitude observed historically in the Central Apennines (thick line) and the predicted rates from characteristic faults-earthquakes, $\mathrm{CH}$ (box symbols). The predicted numbers of events are calculated using slip rates between 0.1 and $2.5 \mathrm{~mm} /$ year on the all faults deviation would produce a very tight likelihood distribution because $n$ faults are producing the target rate. Accordingly, the standard deviation for rate was multiplied by $\operatorname{sqrt}(n)$ to obtain the expected standard deviation for 1 of $n$ faults (in our case, $n=58$ ).

The use of the sum of the squares of the difference between predicted values and observed values as an argument to the exponential function for generating a likelihood distribution is similar to the methodology found in Tarantola and Valette (1982), Tarantola (2005), and Moraes and Scales (2000) for Bayesian inversion.

Not surprisingly, the likelihood distribution is well fitted by a lognormal distribution (Fig. 2). When the target rate values are not logged, the resulting likelihood appears to be a normal distribution rather than lognormal. Our opinion is that the Bayesian calculation works regardless of the distribution shape used for the prior or likelihood but results in a different posterior. We think the properties of the lognormal distributions are to be preferred, given the wide range of slip rate parameters. The likelihood distribution we obtained is somewhat narrower than the prior, and the resulting posterior should be somewhat narrower than each.

Multiplying this likelihood function by the prior distribution, we obtain a posterior slip rate distribution function for those faults to which a slip rate variable from 0.1 to $1.0 \mathrm{~mm} /$ year has been assigned by DISS. This posterior distribution can be approximated by the following lognormal distribution,

$$
\begin{aligned}
f_{\text {posterior }}(x)= & \frac{1}{\sqrt{2 \pi} x 0.12 \ln (10)} \\
& \times\left(\exp \left(-0.5\left(\frac{\ln x-\ln 0.5}{0.12 \ln 10}\right)^{2}\right)\right)
\end{aligned}
$$

which peaks near 0.45 with an SD of 0.12 (Fig. 2). This distribution is usefully narrower than the original prior distribution. The low-probability low slip value has increased from 0.1 to 0.2 , and the low-probability high slip value has decreased from 1.4 to 1.0. For other fault slip rate categories 
ranging over smaller intervals, we assumed a distribution obtained by suitably rescaling Eq. 2 .

\subsection{Deriving a distribution for magnitude uncertainty}

In DISS3.0.4, length and width of MWS were derived from the damage distribution of the historical earthquakes, through the "Boxer" algorithm (Gasperini et al. 1999). It estimates magnitude by the macroseismic intensity reports, then estimates an "axis" by finding an orientation in which the near-field intensity seems to be elongated, and finally, given magnitude and axis, creates a "box" using length and width derived from the empirical relations given by Wells and Coppersmith (1994). Stucchi and Albini (2000) pointed out that a standard deviation of 0.5 magnitude units might be assigned to magnitude assessment from macroseismic data. Pace et al. (2006) observed dispersion on the magnitude values, with a maximum scatter of about 0.3, using different empirical relationships calibrated on normal faulting, in the Central Apennines.

Rather than adopt the above estimates, we directly use equations from Wells and Coppersmith (1994) and consider the variability in fault width and length. The uncertainty distribution of these parameters is assumed to be normal, with means given by values reported in DISS3.0.4 and standard deviations equal to $\pm 20 \%$ of the mean values. In the course of calculating recurrence time distributions (see below), using 1,000 random values for the length and width, we obtained a magnitude uncertainty standard deviation (determined by half the difference between the 16th and the 84th percentiles magnitude values) between 0.1 and 0.3 (Fig. 4). DISS3.0.4 presents ranges in values for estimates of uncertainty, and we assume that the ranges correspond to the \pm 1 SD values, so that our calculated \pm range value (0.1-0.3 magnitude units) equals the one given in DISS3.0.4 and agrees with the one obtained by Pace et al. (2006).

\subsection{Uncertainty estimation for recurrence times}

We use a Monte Carlo approach, based on a random sampling, to capture the uncertainties both in the recurrence time and the occurrence probability of earthquakes in each fault zone. For a given choice of $\alpha$ value, the uncertainty on the recurrence rate is obtained by varying three fault parameters (fault length, fault width, and slip rates) simultaneously in the calculations, using the probability distributions defined in previous subsections. In the course of this calculation, we also calculate the variability of magnitude. We perform 1,000 runs to obtain stable estimates. To

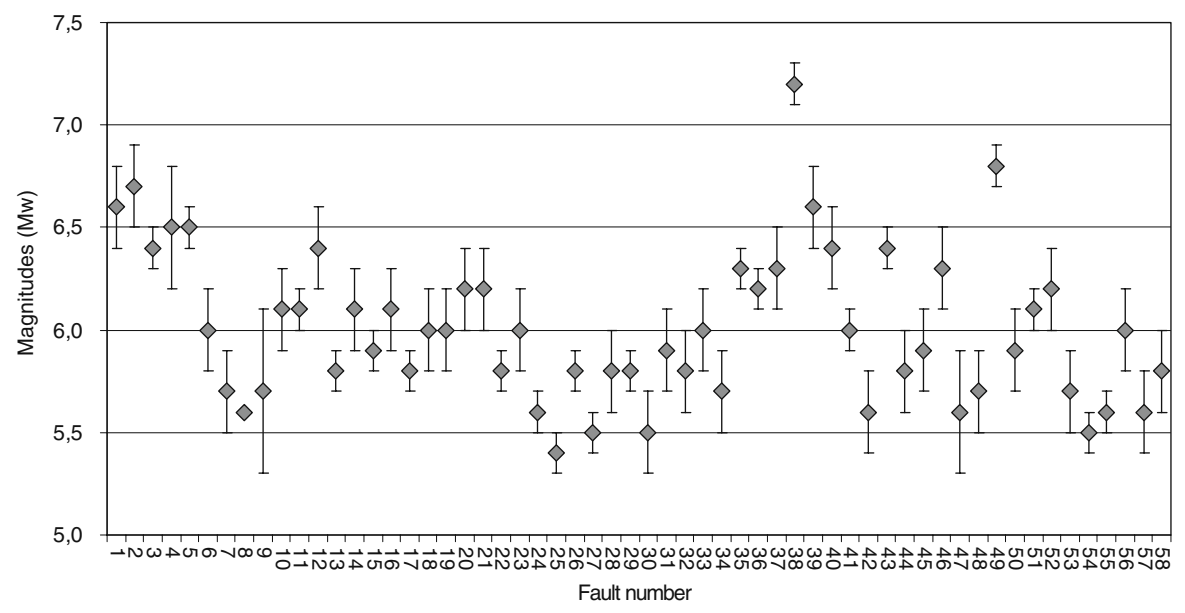

Fig. 4 Characteristic magnitudes $\left(M_{\max }\right)$ and their uncertainties for each seismogenic source: diamonds correspond to magnitudes from DISS3.0.4. Bars show 16 to 84 percentile ranges computed using a Monte Carlo approach under the assumption that uncertainties in the length and the width of the fault are normally distributed with a standard deviation equal to $20 \%$ of their nominal values in DISS3.0.4 


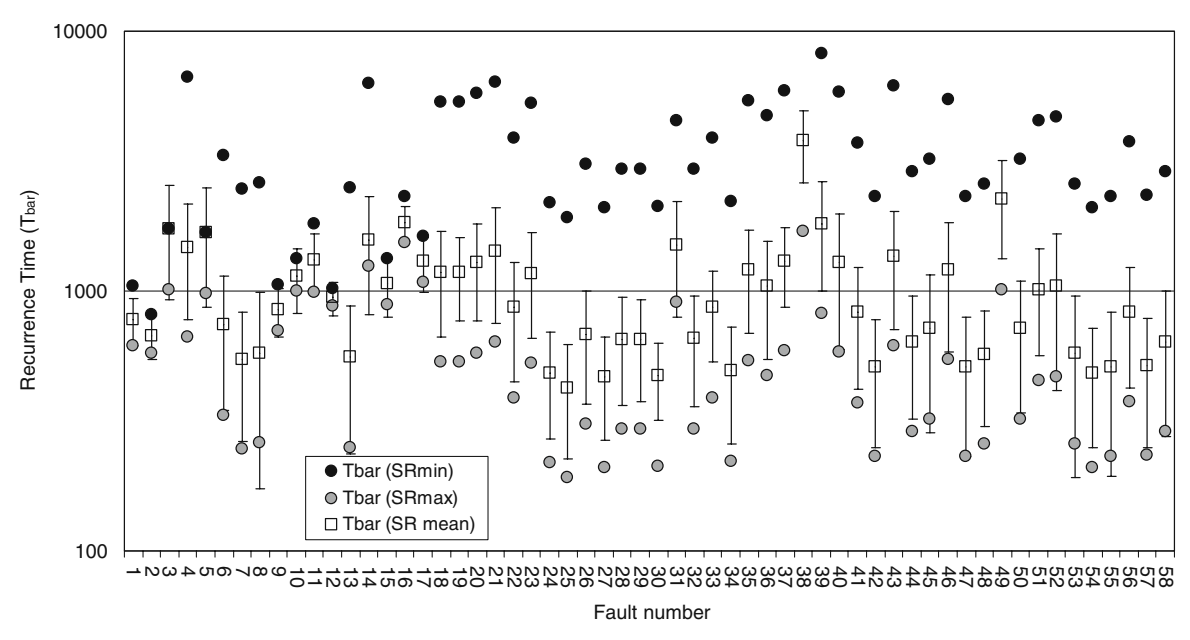

Fig. 5 Recurrence times ( $T_{\text {bar }}$ ) for the ISS and MWS sources: $T_{\text {bar }}$ (SR Min. and SR Max.; circles) is obtained from Eq. 1 using the minimum and maximum slip rates given in DISS3.0.4; $T_{\text {bar }}$ (SR mean) is calculated using Eq. 1 fixing the slip rate, $0.45 \mathrm{~mm} /$ year from the posterior distribution (squares). Uncertainties are computed using a

quantify the variability of each parameter, we select the 16th and the 84th percentiles of 1,000 calculations, which represent the $68 \%$ confidence limits of a probability distribution.

In Fig. 5, we show the uncertainty about the recurrence times coming from slip rate variability and from modifying the length and width in the Monte Carlo process. Specifically, we report the calculated recurrence times using the mean value of the slip rates for each fault and their uncertainties given by the 16 th and the 84 th percentiles of 1,000 simulated values. Resulting recurrence rates change from $15 \%$ to $70 \%$ with respect to their mean value. We also compare these values with those calculated using minimum and maximum slip rates defined in DISS3.0.4.

\section{Earthquake probability models for the Central Apennines}

In contrast to the Poisson model, a timedependent renewal process model is based on the assumption that, after one earthquake on a fault segment, another earthquake on that segment is unlikely until enough time has elapsed to
Monte Carlo simulation, varying the slip according to the posterior slip rate distribution and varying the length and the width of the fault according to their assumed normal distribution. Uncertainty is represented as the range between the 16 and 84 percentiles

build sufficient stress for another rupture (Lindh 1983; Sykes and Nishenko 1984; Nishenko and Buland 1987; Ellsworth 1995; Ogata 1999). Various statistical models have been proposed for the computation of the probability density function for earthquake recurrence intervals, such as Gaussian, lognormal, Weibull, Gamma, and Brownian. In this study, we use the BPT probability model that is based on a simple physical model of the earthquake cycle and has many desirable statistical properties that make it a suitable candidate for describing the statistics of earthquake recurrence. The BPT distribution has the desirable property that the hazard function is asymptotic to some constant level for elapsed times much larger than the average elapsed time, unlike that of the Weibull distribution (but see also Yakovlev et al. 2006), for which the hazard function increases indefinitely, or the lognormal distribution, for which the hazard function decreases to zero (Matthews et al. 2002). The BPT distribution has been widely used in California (WGCEP 2003).

Time-dependent probability functions distribute recurrences around some mean recurrence time $\left(T_{\text {bar }}\right)$, and the width of the distributions represents aleatory variability $(\alpha)$ on recurrence. 
A very narrow width implies very regular recurrence. The probability density for the BPT model is given by:

$$
f(t)=\sqrt{\left(T_{\mathrm{bar}} / 2 \pi \alpha^{2} t^{3}\right) \exp \left[-\left(t-T_{\mathrm{bar}}\right)^{2} / 2 \alpha^{2} T_{\mathrm{bar}} t\right]}
$$

where $t$ is the time. $\alpha$ is a dimensionless measure of aperiodicity given by the ratio of standard deviation of the recurrence times over the mean recurrence time. The smaller are the $\alpha$ values, the higher is the probability of occurrence for elapsed times long compared to the mean recurrence time.

On the other hand, as the $\alpha$ value increases and approaches unity, the process becomes less strongly quasiperiodic and becomes increasingly Poisson like. For a Poisson process, the probability $P$ of occurrence of one or more events, in a time period $T$ of interest, is given by $P=$ $1-\exp (-\mathrm{rT})$, where $r$ is the rate of earthquakes and is the inverse of the average recurrence time. The result is a constant probability of occurrence, rather than one changing with time.

\section{Parameter sensitivity of time-dependent probability calculations}

The probabilities of occurrence for the next event were assessed using Poisson and BPT distributions in the central Apennines. To calculate the timedependent probability of an earthquake of a given magnitude under the time-dependent model, one must know or estimate its mean recurrence time, $\alpha$ value, and elapsed time since the last earthquake of comparable size. These parameters are most commonly drawn from the historic and paleoseismic record.

\subsection{Aperiodicity parameter and elapsed time ratio}

The aperiodicity parameter ( $\alpha$ value) in the BPT distribution is ordinarily derived from the coefficient of variation of actual observed recurrence times on individual faults and can be reinforced with geological evidence (Ellsworth et al. 1999; Cramer et al. 2000). Because paleoseismological data are sparse and almost not available for most of the seismogenic sources in the study region, we did not have enough data of repeated earthquakes to characterize the aperiodicity parameter of each fault. Ellsworth et al. (1999) have shown that sequences of only two or three intervals between events will be of little use for reliable estimation of $\alpha$. By restricting the sequences to those that have at least four closed intervals (i.e., five events), we found only four sequences out of 58 available in the Apennines suitable for analysis. For these four, we calculated the $\alpha$ value using an approach given by Savage (1991). The $\alpha$ values are around 0.22 for the Fucino and the Irpinia faults, 0.48 for the Aremogna-Cinque Miglia fault, and around 0.50 for the Ovindoli-Pezza fault. Of course, these values are very uncertain, having been calculated from small samples, but their values serve for comparison with values found elsewhere. For example; Ellsworth et al. (1999) found from statistical tests that (1) the limited worldwide earthquake recurrence times have a BPT $\alpha$ value of $0.46 \pm 0.32$, (2) the 35 recurrence time sequences examined are compatible with a shape factor of 0.5 , and (3) the 35 earthquake sequences had no systematic differences when grouped by tectonic style. Our calculated values are consistent with this characterization of worldwide values. Accordingly, we used the average value of $\alpha, 0.5$, as a central value for the rest of the faults in the study region, together with this value with plus or minus 0.2 , that is, $0.7,0.5$, and 0.3 .

An illustration of how the $\alpha$ value affects time-dependent results is given in Fig. 6 for the Ovindoli-Pezza and Selci Lama faults. The figure shows the 30-year probability of future earthquake occurrence on these faults for any given elapsed time, using both the Poisson and BPT distributions with the three $\alpha$ values. An average recurrence time of 774 and 472 is taken for Ovindoli-Pezza and Selci Lama faults, respectively Table 2 . The probability of an earthquake during any 30-year interval of time using a Poisson model is about $4 \%$ and $6 \%$ for the two faults, respectively. For a BPT calculation, we present the time since the last earthquake as ratio of that time divided by the mean recurrence time of the earthquake ("elapsed time ratio"). For example, the current elapsed time ratio is obtained 
Fig. 6 Graph showing 30-year probability of earthquake occurrence on the Ovindoli-Pezza and the Selci Lama Faults, assuming a mean 774-year recurrence time for Ovindoli-Pezza and a mean 472-year recurrence time for Selci Lama. Graphs show the results using Brownian Passage Time and Poisson models for recurrence. $\alpha$ is the aperiodicity parameter used to define the dispersion in the density function

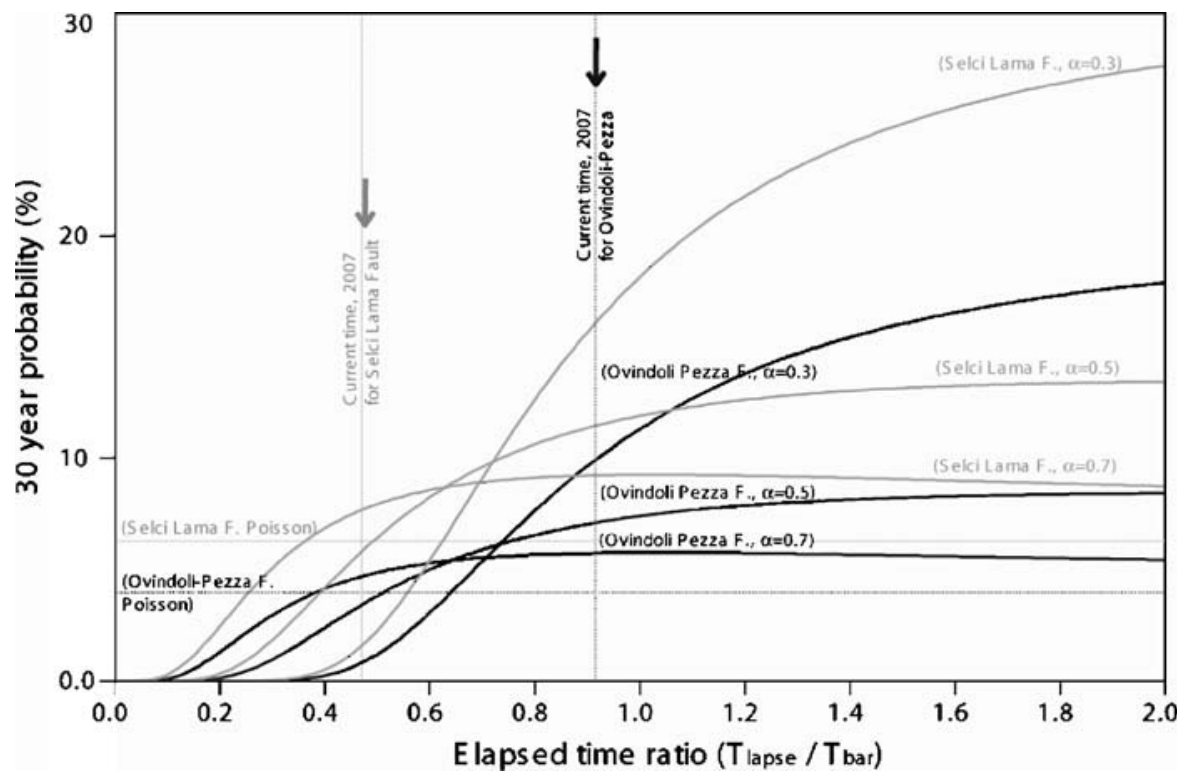

from 707 years (time since the last earthquake) / 774 years (mean recurrence time of the earthquake) $=0.91$ for the Ovindoli-Pezza fault and $218 / 472=0.46$ for the Selci Lama fault. The BPT distribution results in a 30-year probability of about $10 \%$ for $\alpha=0.3$ and $7 \%$ for $\alpha=0.7$ for the Ovindoli-Pezza and Selci Lama faults, respectively. The 30-year probability for an $\alpha$ equal to 0.7 and 0.5 rises above the Poisson probability level earlier in the recurrence cycle than the probability for an $\alpha$ of 0.3 . The probability of occurrence increases with decreasing $\alpha$ for the faults like Ovindoli-Pezza fault from $6 \%$ to $10 \%$, which an elapsed time which is well past about two thirds of the mean recurrence time. For faults like the Selci Lama, which have an elapsed time which is short compared to the mean recurrence time, the occurrence probability decreases from $1 \%$ to $7 \%$ with increasing $\alpha$.

In Fig. 7, we show the probability of occurrence as a function of the elapsed time ratio for each fault in the study region, calculated for $\alpha$ values of 0.3 , 0.5 , and 0.7 and for the Poisson probability. The probability of occurrence increases with decreasing $\alpha$ values for the faults having large elapsed time ratio ( $>0.7-0.8)$, while it decreases with decreasing $\alpha$ values for those faults having small elapsed time ratio (0.1-0.5). Most of the Apennine faults have short elapsed time compared to their mean recurrence time so that the time-dependent probability of occurrence is generally smaller than or similar to the time-independent probability of occurrence. Only two of the 58 faults are near or beyond their mean recurrence time and so have higher probability of occurrence than the timeindependent values. The fault database is likely to be biased to include mainly faults which recently ruptured and thus more easily recognized and therefore are in the beginning of their seismic cycle, whereas the faults which are in the middle or end of their cycle are less likely to be recognized because evidence of rupture is more likely to have been removed. This would explain the fact that, for most of the faults studied, the probabilities according to the BPT model are smaller than the Poissonian probabilities.

In order to characterize the impact of high periodicity on occurrence probabilities for an individual fault, we examine the factor between the mean occurrence probabilities for $\alpha=0.3$ and the occurrence probabilities for $\alpha=0.5$ and 0.7 and the Poisson model (Fig. 8). This factor is changing between 0.0 and 3.0 as a function of the elapsed time ratio. The factor is around 2-3 for the faults with large elapsed time ratio (greater than 0.8), but for faults with small elapsed time ratios (less than 0.4) this factor is near 0. For the majority of the faults, the assumption of $\alpha=0.3$ produces 


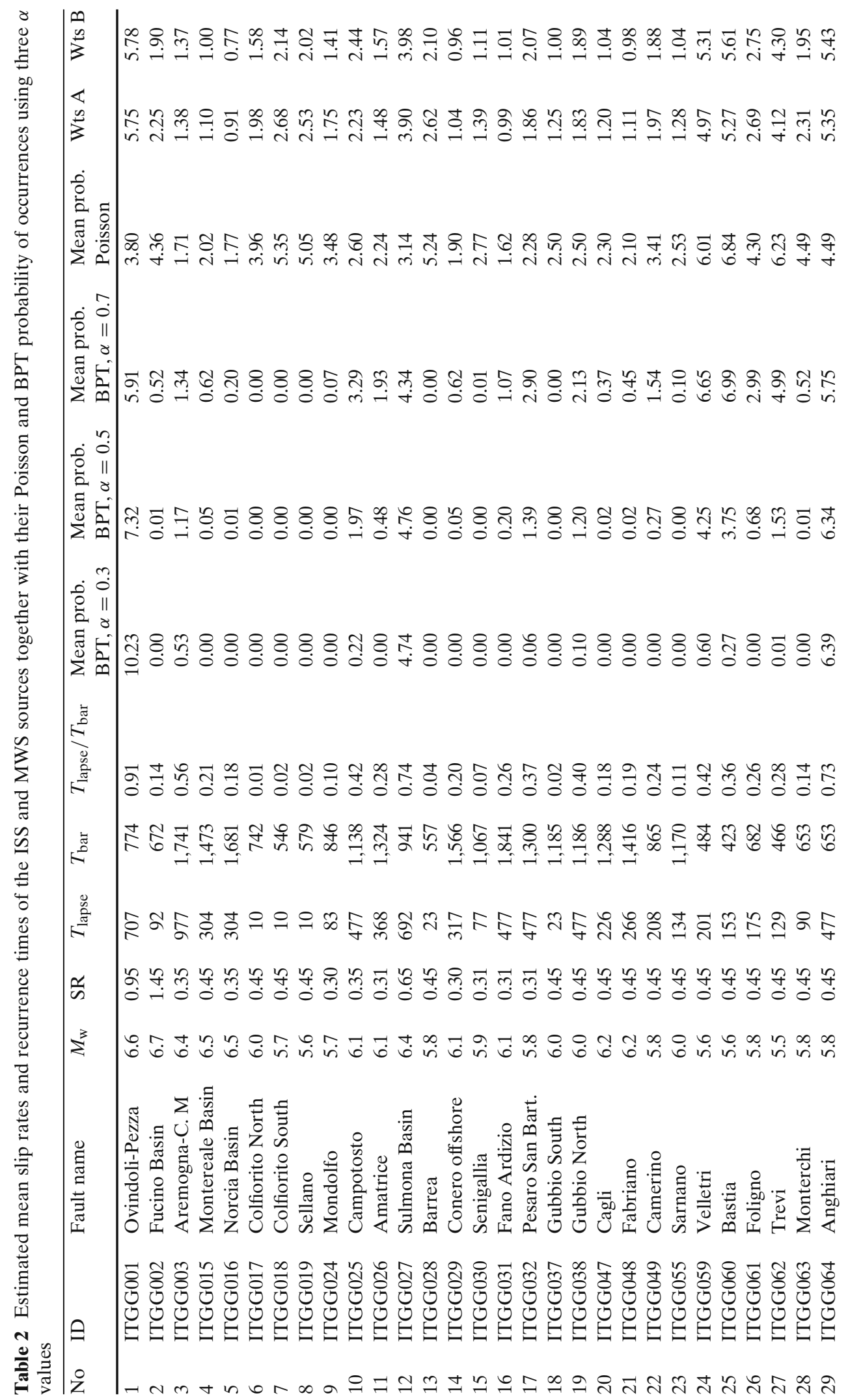




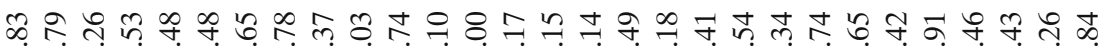

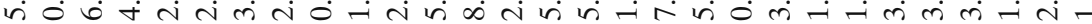

舟

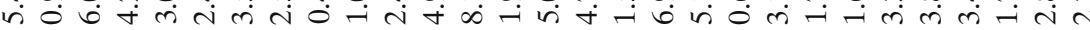

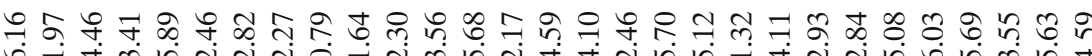

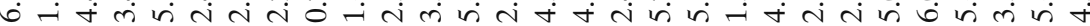

तุ

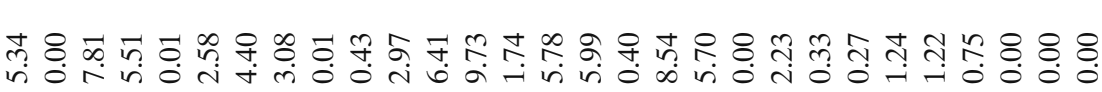

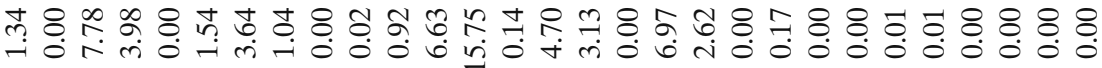

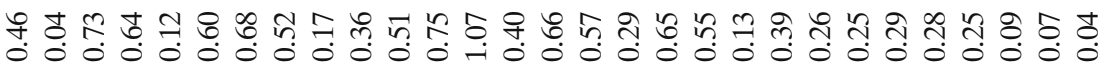

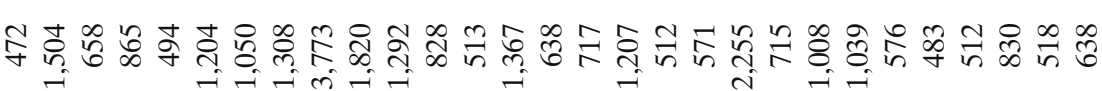

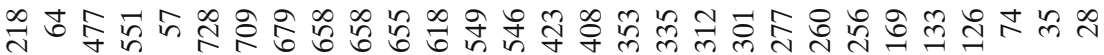

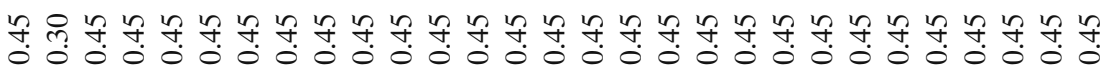

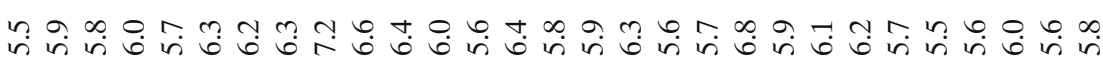

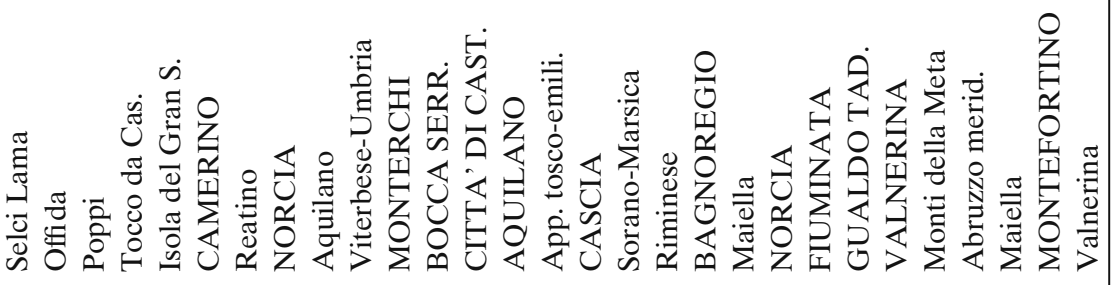

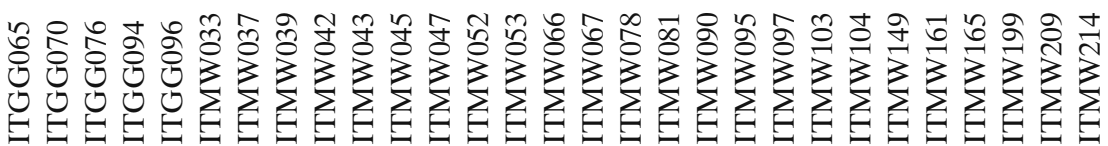
পு 
Fig. 7 Diagram showing the probabilities of occurrence from the BPT model for each fault, calculated for $\alpha$ values of $0.3,0.5$, and 0.7 and for the Poisson probability as a function of the elapsed time ratio on the fault ( $\left.T_{\text {lapse }} / T_{\text {bar }}\right)$

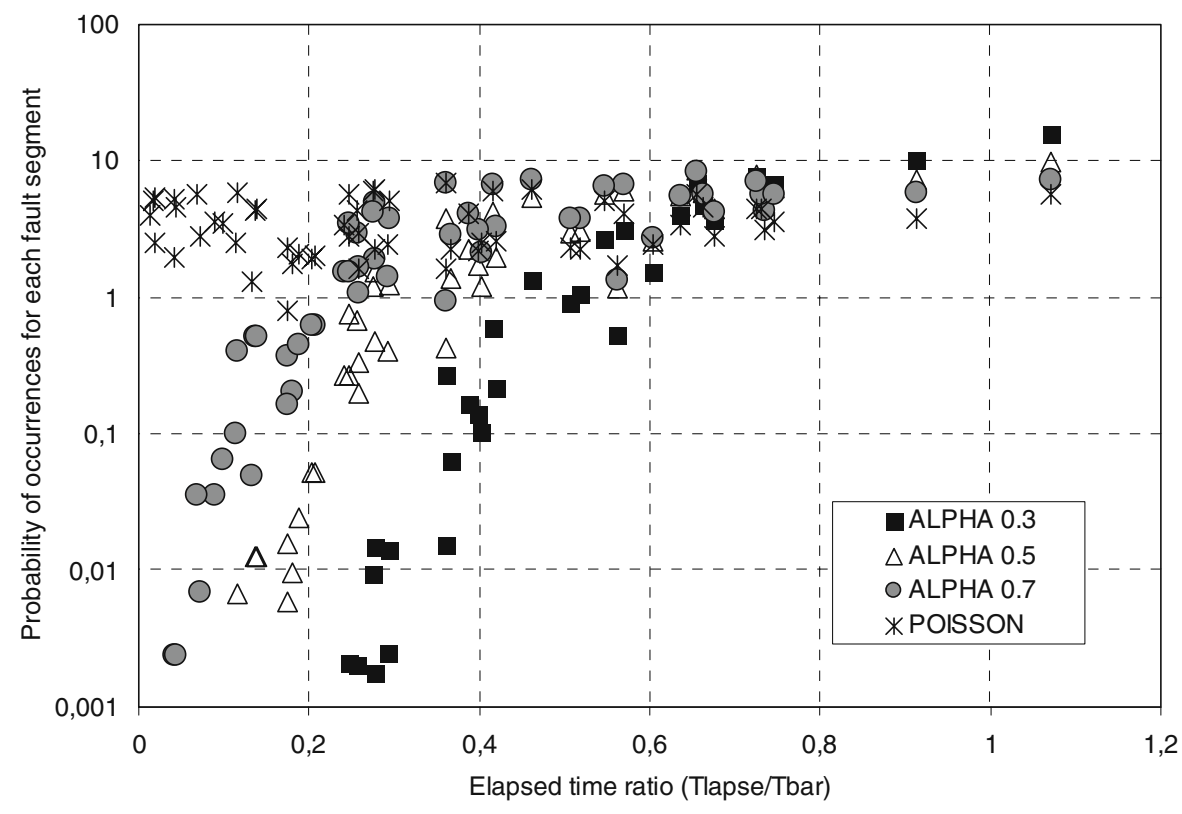

very low occurrence probabilities. If time dependence gives a very low occurrence probability and, hence, a low probabilistic ground motion on a hazard map, the civil authorities might prefer using a time-independent assumption in order to arrive at higher probabilistic ground motion design levels, which would provide greater protection if an earthquake should occur.

\subsection{Uncertainty distributions for the time-dependent and time-independent probability of occurrences}

We calculated the uncertainty distributions in the probability of occurrence, for the individual sources, using a Monte Carlo analysis that allows all parameters to vary according to their speci-
Fig. 8 Diagram showing the effect of time dependence on the ratio of probability of occurrence on an individual fault for $\alpha=0.3$ to the probability of occurrence for $\alpha=0.5$ and 0.7 and the Poisson model, using nominal parameter values. Notice that, for elapsed time ratios smaller than 0.6 to 0.8 , the use of 0.3 produces a smaller probability of occurrence than do less strongly periodic time dependence parameters

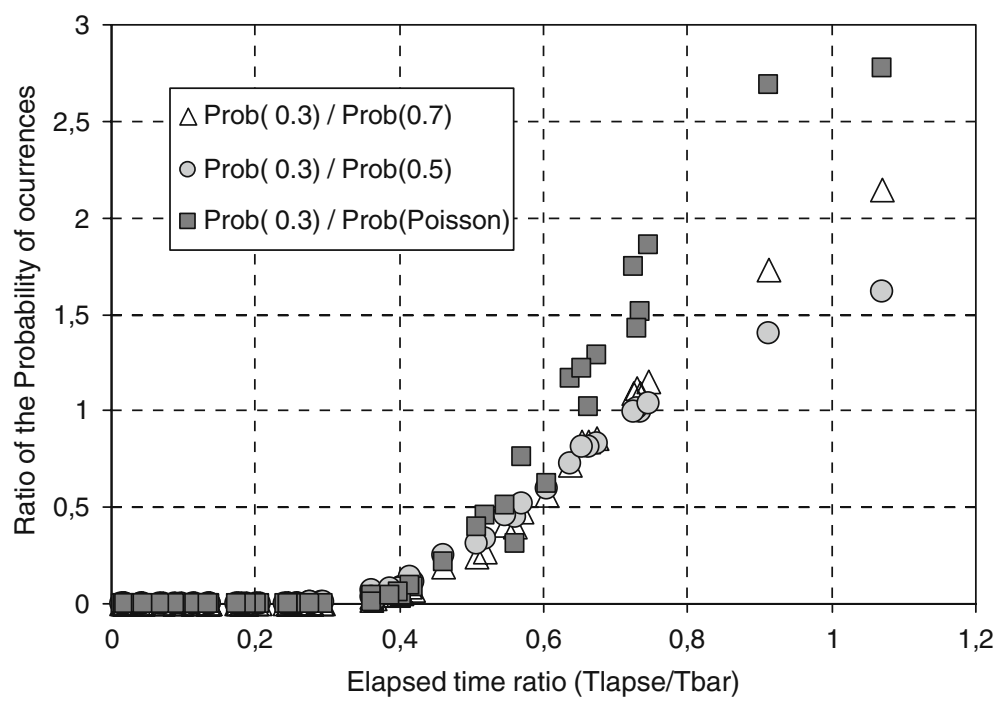


Elasped time ratio (Tlapsed/Tbar)

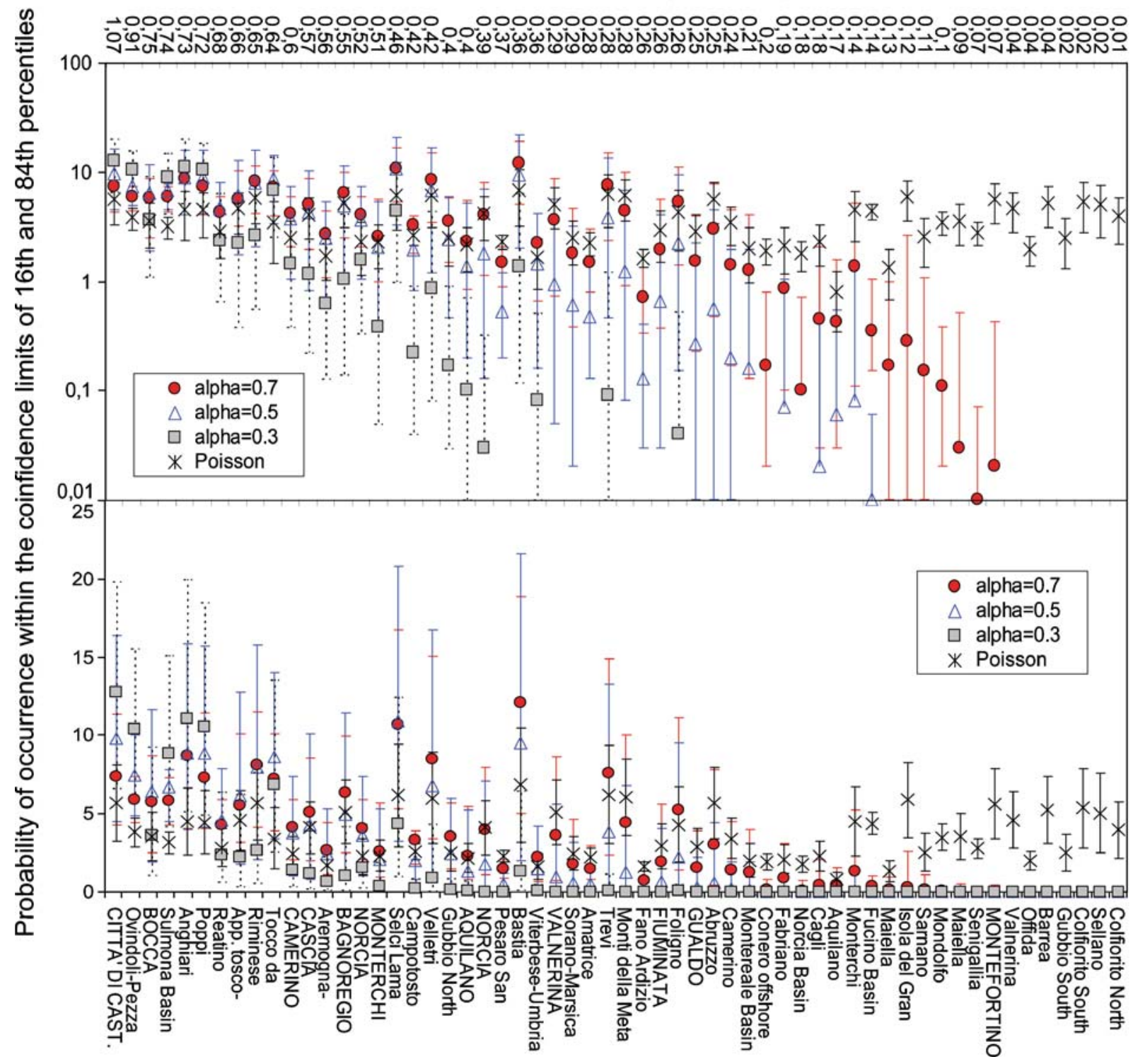

Fig. 9 Probabilities of occurrence for a 30-year period of time (2007-2037) using both log and arithmetic scales for the seismogenic fault sources for both the Poisson and BPT models for $\alpha$ values of $0.3,0.5$, and 0.7 . Uncertainties are presented as a range between the 16th and 84th percentiles fied probability distributions. Details on the basic parameters used and on the methodology are given in "Section 4." We performed 1,000 runs of varying source parameters (length, width, and slip rates) and calculated the time-dependent probability of occurrences for each of the $\alpha$ values separately. These simulated occurrence probabilities for each fault were sorted into ascending order and the 16th and 84th percentile values are determined. Figure 9 shows the mean timeindependent and time-dependent probability of occurrence for each $\alpha$ value along with the 16 th and 84th percentiles of the corresponding simulated distribution for each fault segment. In general, for small $\alpha$ values, the percentile range (84th-16th) gets larger on the faults that have 


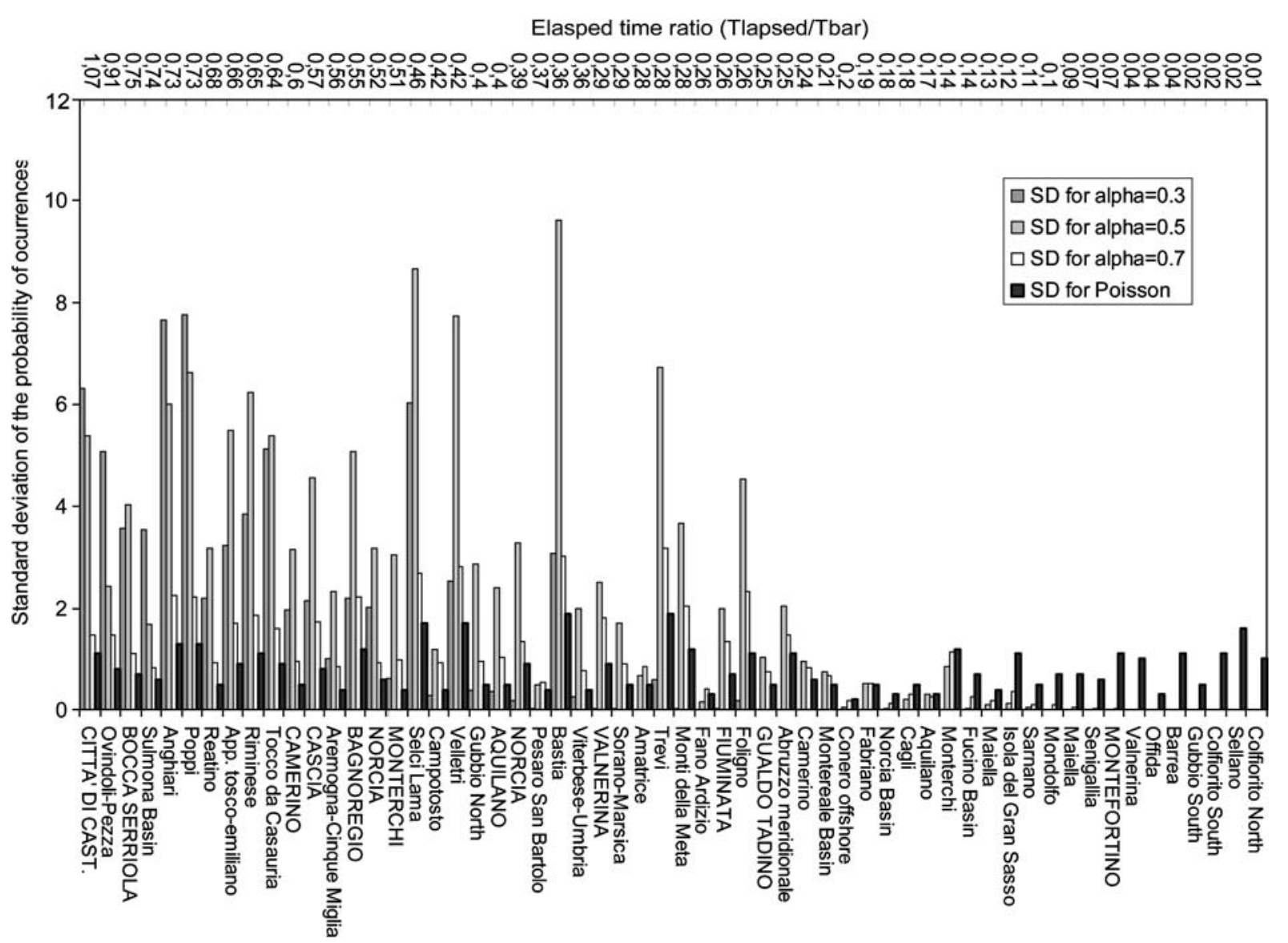

Fig. 10 Estimated standard deviations (in percent) of the Poisson and BPT 30-year occurrence probabilities for each fault and $\alpha$ value

long elapsed time. Time-independent occurrence probabilities and their uncertainty percentiles are higher than those of time-dependent for the faults that have small elapsed time ratios $(0.25$ or less). On the $\log$ scale, the ratio of the 84th to 16th percentile can be seen to be very large, in many cases as much as two orders of magnitude. Figure 10 shows the estimated standard deviations of the occurrence probabilities for each fault. These values most of the time are as high as or exceed the expected values.

\section{Probability of occurrence in 30 years (2007-2037)}

The mean occurrence probabilities under the Poisson model range from $1.0 \%$ to $7 \%$. The stan- dard deviation of this probability on an individual fault is about $1.0 \%$. The mean occurrence probability under time dependence for the modeled $\alpha$ values of $0.3,0.5$, and 0.7 runs from less than $1.0 \%$ to as much as $15 \%$ (Table 2 ). In other words, considering the choice involved invoking a BPT model has increased the overall uncertainty in occurrence probability compared to the uncertainty of the Poisson model.

In the Poisson model, the hazard is not sensitive to the recency of rupture on the faults. Generally, but not always, time dependence raises the probabilities except for those faults that have had earthquakes recently. The Citta' di Castello, Ovindoli-Pezza faults generally have high mean probability of occurrence, $16 \%$ and $10 \%$, respectively, relative to the time-independent probability. This is because these faults are late in their 
seismic cycles. The Colfiorito South and North, Gubbio South, and Sellano faults, on the other hand, have time-dependent occurrence probability that is lower than the time-independent occurrence probability due to the relatively short elapsed time since the last earthquake, which places these faults in the first half of their seismic cycles. In Fig. 11, we show the maximum calculated occurrence probabilities under the Poisson and BPT model, at the 84th percentile for the $\alpha$ value that gives the largest probability. Even for this worst-case assumption, more than half of the sources have low probabilities of having an event, even at the 84th percentiles, typically around $5 \%$ in the next 30 years. Thirteen of the faults have a probability greater than $10 \%$. Only four of those have a probability of occurrence higher than $20 \%$. These four segments are (1) Anghiari, $M_{\mathrm{w}}=5.8$ (20.5\%); (2) Poppi, $M_{\mathrm{w}}=5.8$ (20.0\%); (3) Selci Lama, $M_{\mathrm{w}}=5.5$ (20.4\%); (4) Bastia, $M_{\mathrm{w}}=5.4(20.8 \%)$. These results show that as far as source rupture probability is concerned sources having moderate magnitude $\left(M_{\mathrm{w}}\right.$ around 5.4-5.8) and therefore relatively short return times can dominate sources having larger mag- nitude, with correspondingly longer mean return times.

As far as time dependence is concerned, this paper has focused on the sensitivity of probability of occurrence on the choice of earthquake recurrence model. To provide an estimate for probability by combining the time-dependent results would require assigning weights for the $\alpha$ parameter, and producing smoothness in the resulting distribution would require more closely spaced values of $\alpha$. This would be beyond the scope of our present study but would be sensible for further studies on individual faults. However, the general effect of incorporating a distribution on $\alpha$ value can be estimated by averaging the results for values $0.3,0.5,0.7$, and 1.0 (Poisson) with suitable weights. One set might be to weigh the Poisson model $50 \%$, and for the BPT model make the aperiodicity choice 0.5 twice as likely as each of the others. The resulting weights would be 0.125 , $0.250,0.125$, and 0.5, respectively. Call this set of weights A. Another choice might prefer biasing toward time independence using weights $0.1,0.2$, 0.3 , and 0.4 , respectively. Call this set B. The resulting averages can be found in Table 2 .

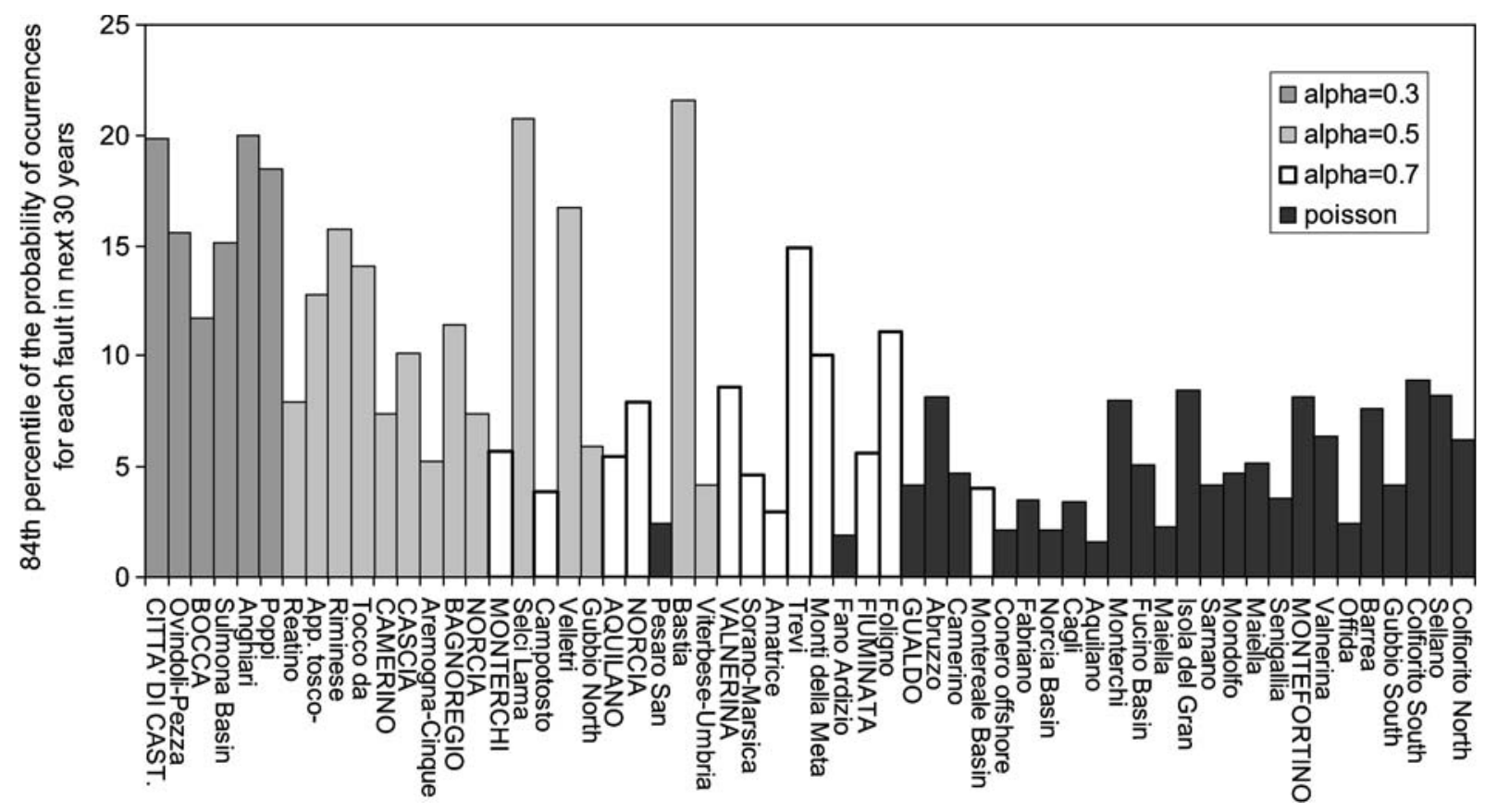

Fig. 11 Maximum 84th percentile probability of occurrence in the next 30 years (2007-2037) calculated using BPT and Poisson models for the fault segments of the central Apennines for the $\alpha$ value that gives the largest probability 
We observe the following about the results:

1. Consider three faults Anghiari, Selci Lama, and Bastia. For Anghiari, the mean percentile probabilities for $\alpha$ values $0.3,0.5,0.7$, and 1.0 are about $6.39,6.34,5.75$, and 4.49 , respectively. For weights A, the overall average is 5.3475 ; for weights $\mathrm{B}$, it is 5.428 . For Selci Lama; 1.34, 5.34, 7.20, 6.16. A: 5.4825, B: 5.826. For Bastia; 0.27, 3.75, 6.99, 6.84. A: 5.265, B: 5.61. Although these faults are quite different in their time-dependent behavior, under weighted averaging, the calculated probabilities are too close to provide any useful distinction between them. That is, we cannot distinguish any longer between a fault which is insensitive to time dependence, one that is sensitive, and one that is very sensitive to choice of time-dependent parameter.

2. For almost $80 \%$ of the 58 faults, the overall average lies either between the values for 0.7 and $1.0(53 \%)$ or near the value of $0.7(26 \%)$. This indicates that weak time dependence $(0.7)$ is a reasonable choice in a single calculation.

3. If, for each fault, you look at the ratio of the overall mean to the Poisson mean, the average of the 58 ratios is 0.76 , and half the faults have ratios running from 0.66 to 0.50 , that is, the occurrence probabilities have decreased from $33 \%$ to $50 \%$. On the other hand, of the faults showing increases, only 13 sources have an increase of more than $10 \%$, the largest being only a $50 \%$ increase.

So the overall effect of incorporating weights in $\alpha$ value is to decrease the occurrence probability below the Poisson level and increase the probability for only a few faults and that by only a small amount. We think that, in terms of useful information, the sensitivity results provide better information for mitigation-selection of the more likely dangerous faults and guidance in the choice of $\alpha$ value for use in probabilistic ground motions for use in seismic design.

\section{Conclusions and discussions}

In this study, we calculated probabilities of occurrence in the next 30 years for each seismogenic source in the central Apennines using the Poisson model and the Brownian passage time distribution. The present study does not quantify uncertainties in the ground motions that are produced by the faults for PSHA purposes. However, it is important to understand the impact of earthquake recurrence model on PSHA estimates. Recently, in the central Apennines, there have been several studies on the application of BPT and Poisson model in the seismic hazard maps, in terms of expected peak ground acceleration (PGA) values in the next 50 years (Akinci et al., manuscript in preparation; Akinci et al. 2007; Pace et al. 2006). Even though these studies used different geologic data compilation and different $\alpha$ values for each fault, their general results are similar in the impact of the time-dependent model. That is, the contribution of the recently active source faults vanishes in the overall seismic hazard-the timedependent PGA values are $20 \%$ lower than the Poissonian ones. On the other hand, some source faults with long elapsed time become the most hazardous sites, where the time-dependent PGA values are about $50 \%$ higher than those of the Poissonian model.

The present study has highlighted those sources in which time dependence produces a significant increase in hazard. These are worthy of further study. On the other hand, for many sources, time dependence produces a decrease in hazard, a decrease it may not be prudent to credit.

It is clear that slip rate uncertainty is a major contributor to the uncertainty of the probabilities. It is possible that likelihood functions based on historical recurrences for individual sources or based on regional geodetic constraints might further narrow the slip rate uncertainty.

For at least a few of the sources, the assignment of the previous earthquake date as the limit of completeness results in an underestimation of the probabilities in the time-dependent cases. Incorporation of a distribution function for that date would be helpful in a more focused study of these faults.

In this study, we consider only the elapsed time as a first-order parameter in calculating time-dependent earthquake probabilities. Other factors such as static elastic fault interactions, viscoelastic stress transfer, and dynamic stress 
changes from earthquakes on nearby faults may also influence the short-term probabilities for earthquake recurrence. To the extent that clustering may be present in the historical catalog, related studies would be important.

It is important to note that the probabilities presented here are not intended to represent absolute estimates, but they have only a relative meaning to help in understanding the models used and their impact on regional planning. We believe that the results obtained can suggest future research to resolve some of the important questions that impact the occurrence probabilities. In addition to new information on earthquake recurrence, rupture histories and new fault sources from geological and paleoseismological studies, we would hope for a more focused research on time dependence and developing likelihood functions based on individual fault earthquake histories and regional strain.

Acknowledgements The authors are grateful to Sebastian Hainzl and an anonymous reviewer for their comments and criticisms. This study is supported by the Dipartimento della Protezione Civile funds of the project "Valutazione del potenziale sismogenetico e probabilità dei forti terremoti in Italia" coordinated by Gianluca Valensise and Dario Slejko. The final results released by this study can be found at the web site address: http://web.ingv.it/ progettiSV / Progetti / Sismologici/ sismologici_con_frame. htm. During this work, David Perkins has been supported by this grant for 2 months at the Istituto Nazionale di Geofisica e Vulcanologia, Rome, Italy.

\section{References}

Akinci A, Mueller C, Malagnini L, Lombardi AM (2004a) A probabilistic seismic hazard assessment for the Alps and Apennines (Italy) using historical seismicity and new predictive ground-motion relationships. Boll Geofis Teor Appl 45(4):285-304

Akinci A, Galadini F, Pantosti D, Petersen M, Malagnini L (2004b) A time-dependent probabilistic seismic hazard model for the Central Apennines (Italy). Abstract, AGU, 2004 Fall meeting, San Francisco, USA

Akinci A, Perkins D, Lombardi AM (2007) A Monte Carlo approach in estimating endogenous uncertainties for a seismic hazard assessment of the Central Apennines, Italy. Seismological Society of America, Annual Meeting. Seismol Res Lett 78(2):244

Basili R, Valensise G, Vannoli P, Burrato P, Fracassi U, Mariano S, Tiberti MM, Boschi E (2008) The data- base of individual seismogenic sources (DISS), version 3: summarizing 20 years of research on Italy's earthquake geology. Tectonophysics 453:20-43. doi: 10.1016/j.tecto.2007.04.014

Beauval C, Scotti O (2004) Quantifying sensitivities of PSHA for France to earthquake catalog uncertainties, truncation of ground-motion variability, and magnitude limits. Bull Seismol Soc Am 94:1579-1594. doi:10.1785/012003246

Bommer J, Scherbaum F, Bungum H, Cotton F, Sabetta F, Abrahamson NA (2005) On the use of logic trees for ground-motion prediction equations in seismichazard analysis. Bull Seismol Soc Am 95:377-389. doi:10.1785/0120040073

Cao T, Petersen M, Frankel A (2005) Model uncertainties of the 2002 update of California seismic hazard maps. Bull Seism Soc Am 95:2040-2057

CPTI Working Group (2004) Catalogo Parametrico dei Terremoti Italiani, version 2004 (CPTI04). INGV, Milan, available from http://emidius.mi.ingv.it/CPTI/

Cramer CH (2001) A seismic hazard uncertainty analysis for the New Madrid seismic zone. Eng Geol 62:251266. doi:10.1016/S0013-7952(01)00064-3

Cramer CH, Petersen MD, Reichle MS (1996) A Monte Carlo approach in estimating uncertainty for a seismic hazard assessment of Los Angeles, Ventura and Orange Counties, California. Bull Seismol Soc Am 86(6):1681-1691

Cramer CH, Petersen MD, Cao T, Toppozada TR, Reichle M (2000) A time-dependent probabilistic seismichazard model for California. Bull Seismol Soc Am 90(1):1-21. doi:10.1785/0119980087

D'Addezio G, Masana E, Pantosti D (2001) The Holocene paleoseismicity of the Aremogna-Cinque Miglia Fault (Central Italy). J Seismol 5:181-205. doi: 10.1023/ A:1011403408568

DISS Working Group (2007) Database of individual seismogenic sources (DISS), version 3.0.4: a compilation of potential sources for earthquakes larger than M 5.5 in Italy and surrounding areas. http://www.ingv.it/DISS/

Ellsworth WL (1995) Characteristic earthquakes and longterm earthquake forecasts: implications of central California seismicity. In: Cheng FY, Sheu MS (eds) Urban disaster mitigation: the role of science and technology. Elsevier, Amsterdam, pp 1-14

Ellsworth WL, Matthews MV, Nadeau RM, Nishenko SP, Reasenberg PA, Simpson RW (1999) A physicallybased earthquake recurrence model for estimation of long-term earthquake probabilities: U. S. Geological Survey, OFR 99-522, p 23

Erdik M, Demircioglu M, Sesetyan K, Durukal E, Siyahi B (2004) Earthquake hazard in Marmara Region, Turkey. Soil Dyn Earthqu Eng 24:605-631. doi:10.1016/j.soildyn.2004.04.003

Faenza L, Marzocchi W, Boschi E (2003) A nonparametric hazard model to characterize the spatiotemporal occurrence of large earthquakes; an application to the Italian catalog. Geophys J Int 155:521-531. doi:10.1046/j.1365-246X.2003.02068.x 
Field EH, Johnson DD, Dolan JF (1999) A mutually consistent seismic-hazard source model for Southern California. Bull Seismol Soc Am 89:559-578

Galadini F, Galli P (1999) The Holocene paleoearthquakes on the 1915 Avezzano earthquake faults (central Italy): implications for active tectonics in the Central Apennines. Tectonophysics 308:143-170. doi:10.1016/ S0040-1951(99)00091-8

Gasperini P, Bernardini F, Valensise G, Boschi E (1999) Defining seismogenic sources from historical earthquake felt reports. Bull Seismol Soc Am 89:94110

Hanks TC, Kanamori H (1979) A moment magnitude scale. J Geophys Res 84(B5):2348-2350. doi:10.1029/ JB084iB05p02348

Kagan YY, Jackson DD (1991) Long-term earthquake clustering. Geophys J Int 104:117-133. doi: 10.1111/j.1365-246X.1991.tb02498.x

Kanamori H, Anderson DL (1975) Theoretical basis of some empirical relations in seismology. Bull Seismol Soc Am 65:1073-1095

Lindh AG (1983) Preliminary assessment of long-term probabilities for large earthquakes along selected segments of the San Andreas fault system in California. U.S. Geological Survey Open-File Report 83-63, p 15

Lombardi AM, Marzocchi W (2007) Evidence of clustering and nonstationarity in the time distribution of large worldwide earthquakes. J Geophys Res 112:B02303. doi:10.1029/2006JB004568

Lombardi AM, Akinci A, Malagnini L, Mueller CH (2005) Uncertainty analysis for seismic hazard in Northern and Central Italy. Ann Geophys 48:853-865

Mancini M, D'Anastasio E, Barbieri M, De Martini PM (2007) Geomorphological, paleontological and 87Sr/ $86 \mathrm{Sr}$ isotope analyses of early Pleistocene paleoshorelines to define the uplift of Central Apennines (Italy). Quat Res 67(3):487-501. doi:10.1016/j.yqres.2007. 01.005

Mariani S, Mainiero M, Barchi M, van der Borg K, Vonhof H, Montanari A (2007) Use of speleologic data to evaluate Holocene uplifting and tilting: an example from the Frasassi anticline (Northeastern Apennines, Italy). Earth Planet Sci Lett 257:313-328. doi:10.1016/j.epsl.2007.02.045

Marzocchi W, Selva J, Piersanti A, Boschi E (2003) On the long-term interaction among earthquakes: some insights from a model simulation. J Geophys Res 108(B11):2538. doi:10.1029/2003JB002390

Matthews MV, Ellsworth WL, Reasenberg PA (2002) A Brownian model for recurrent earthquakes. Bull Seismol Soc Am 92:2233-2250. doi:10.1785/0120010267

McCann WR, Nishenko SP, Sykes LR, Krause J (1979) Seismic gaps and plate tectonics: seismic potential for major boundaries. Pure Appl Geophys 117:1082-1147. doi:10.1007/BF00876211

Moraes FS, Scales JA (2000) Local Bayesian inversion: theoretical developments. Geophys J Int 141:713-723. doi:10.1046/j.1365-246x.2000.00110.x

Morgan TP, Carlson JM (2006) Methodologies for earthquake hazard assessment: model uncertainty and the WGCEP-2002 forecast. Bull Seismol Soc Am 96:624-633

Nishenko SP, Buland R (1987) A generic recurrence interval distribution for earthquake forecasting. Bull Seismol Soc Am 77:1382-1399

Ogata Y (1999) Estimating the hazard of rupture using uncertain occurrence times of paleoearthquakes. J Geophys Res 104B(8):17995-18014

Pace B, Peruzza L, Lavecchia G, Boncio P (2006) Layered seismogenic source model and probabilistic seismichazard analyses in Central Italy. Bull Seismol Soc Am 96:107-132. doi:10.1785/0120040231

Pantosti D, D’Addezio G, Cinti FR (1996) Paleoseismicity of the Ovindoli-Pezza fault, Central Apennines, Italy: a history including a large, previously unrecorded earthquake in Middle Ages (886-1300 A.D.). J Geophys Res 101:5937-5959. doi:10.1029/95JB03213

Peruzza L (2006) Trials and ideas for the 3rd generation of Italian seismic hazard maps. Boll Geofis Teor Appl 47(4):515-548

Peruzza L, Pantosti D, Slejko D, Valensise G (1997) Testing a new hybrid approach to seismic hazard assessment: an application to the calabrian arc (Southern Italy). Nat Hazards 14:113-126. doi:10.1007/ BF00128260

Petersen MD, Cao T, Campbell KW, Frankel AD (2007) Time-independent and time-dependent seismic hazard assessment for the State of California: uniform California earthquake rupture forecast model 1.0. Seismol Res Lett 78(1):99-109. doi:10.1785/ gssrl.78.1.99

Reid HF (1910) The mechanics of the earthquakes, vol. 2 of the California Earthquake of April 18 1906. Report of the State Earthquake Investigation Commission. Carnegie Institution of Washington Publication 87

Rhoades DA, Evison FF (2004) Long-range earthquake forecasting with every earthquake a precursor according to scale. Pageoph 161:47-72

Romeo R (2005) Earthquake hazard in Italy, 20012030. Nat Hazards 36:383-405. doi:10.1007/s11069005-1939-1

Savage JC (1991) Criticism of some forecasts of the national earthquake prediction council. Bull Seismol Soc Am 81:862-881

Schwartz DP, Coppersmith KJ (1984) Fault behaviour and characteristic earthquakes: examples from the Wasatch and San Andreas Fault Zones. J Geophys Res 89:5681-5698. doi:10.1029/JB089iB07p05681

Shimazaki K, Nakata T (1980) Time-predictable recurrence model for large earthquakes. Geophys Res Lett 7:279-282. doi:10.1029/GL007i004p00279

Stucchi M, Albini P (2000) Quanti terremoti distruttivi abbiamo perso nell'ultimo millennio? Spunti per la definizione di un approccio storico alla valutazione della completezza. In: Galadini F, Meletti C, Rebez A (eds) Le ricerche del GNDT nel campo della pericolosità sismica (1996-1999). CNR-GNDT, Rome, pp 333-343

Stucchi et al (2007) DBMI04, il database delle osservazioni macrosismiche dei terremoti italiani utilizzate per la compilazione del catalogo parametrico CPTI04. 
http://emidius.mi.ingv.it/DBMI04/, Quaderni di Geofisica, 49, p 38

Sykes LR, Nishenko S (1984) Probabilities of occurrence of large plate rupturing earthquakes for the San Andreas, San Jacinto and Imperial faults, California, 1983-2003. J Geophys Res 89:905-5927. doi:10.1029/ JB089iB07p05905

Tarantola A (2005) Inverse problem theory and methods for model parameter estimation. SIAM, Philadelphia

Tarantola A, Valette B (1982) Inverse problems=quest for information. J Geophys 50:159-170

Valensise G, Pantosti D (eds) (2001) Database of potential sources for earthquakes larger than M 5.5 in Italy, version 2.0. Ann Geofis 44(suppl):797-964

Vannoli P, Basili R, Valensise G (2004) New geomorphic evidence for anticlinal growth driven by blind-thrust faulting along the northern Marche coastal belt (central Italy). J Seismol 8:297-312. doi:10.1023/ B:JOSE.0000038456.00574.e3

Wells D, Coppersmith (1994) New empirical relationships among magnitude, rupture length, rupture width, rupture area and surface displacement. Bull Seismol Soc Am 84:974-1002

Working Group CPTI (2004) Catalogo Parametrico dei Terremoti Italiani, versione 2004 (CPTI04). INGV, Bologna. http://emidius.mi.ingv.it/CPTI/

Working Group on California Earthquake Probabilities (WGCEP02) (2003) Earthquakes probabilities in the San Francisco Bay region: 2002 to 2031. USGS, Openfile Rept. 03-214, 2003. http://pubs.usgs.gov

Yakovlev G, Turcotte D, Rundle J, Rundle P (2006) Simulation-based distributions of earthquake recurrence times on the San Andreas Fault system. Bull Seismol Soc Am 96:1995-2007. doi:10.1785/0120050183 